\title{
The effect of composition on structural, thermal, redox and bioactive properties of Ce-containing glasses
}

\author{
Valentina Nicolini ${ }^{a}$, Elena Varini ${ }^{a}$, Gianluca Malavasi ${ }^{a}, *$, Ledi Menabue ${ }^{a}$, Maria Cristina Menziani ${ }^{a}$, \\ Gigliola Lusvardi a , Alfonso Pedone ${ }^{\mathrm{a}}$, Francesco Benedetti ${ }^{\mathrm{b}, \mathrm{c}}$, Paola Luches ${ }^{\mathrm{c}}$
}

a Department of Chemical and Geological Sciences, University of Modena and Reggio Emilia, via Campi 103, 41125 Modena, Italy

${ }^{\mathrm{b}}$ Department of Physics, Informatics and Mathematics, University of Modena and Reggio Emilia, via Campi 213/a, 41125 Modena, Italy

c Istituto Nanoscienze-CNR, via Campi 213/a, 41125 Modena, Italy

\section{A R T I C L E I N F O}

\section{Article history:}

Received 13 November 2015

Received in revised form 4 February 2016

Accepted 15 February 2016

Available online 17 February 2016

\section{Keywords:}

Bioactive glasses

Cerium

Catalase mimetic activity

Bioactivity

SEM-EDS

XPS

Molecular dynamics simulations

\begin{abstract}
A B S T R A C T
The effect of phosphate on the ability of Ce-containing bioactive glasses to inhibit oxidative stress was studied on compositions based on Hench $\left(46.2 \% \mathrm{SiO}_{2}-24.3 \% \mathrm{Na}_{2} \mathrm{O}-26.9 \% \mathrm{CaO}-2.6 \mathrm{P}_{2} \mathrm{O}_{5}, \mathrm{~mol} \%\right)$ and Kokubo $\left(50.0 \% \mathrm{SiO}_{2}-\right.$ $25.0 \% \mathrm{Na}_{2} \mathrm{O}-25.0 \% \mathrm{CaO}$ ) glasses. In particular, the reduction of catalase mimetic activity of Ce-containing glasses due to the presence: i) of $\mathrm{P}_{2} \mathrm{O}_{5}$ in the glass compositions, and ii) of phosphate groups in the solution employed for catalase mimetic activity tests was explained and rationalized by combining SEM, XPS, XRD, DTA, FT-IR and UVvis experiments with Molecular Dynamics simulations.

The results suggest that the Ce ions play a different structural role in the two series of glasses. In particular, in phosphate free glasses Ce is coordinated by non-bridging oxygens (NBOs) originated from the disruption of the silicate network, whereas in phosphate containing glasses the NBOs around Ce ions belong to orthophosphate groups. The latter groups stabilize the $\mathrm{Ce}^{3+}$ species subtracting them from the interconversion process between $\mathrm{Ce}^{3+}$ and $\mathrm{Ce}^{4+}$, which is of fundamental importance for the exhibition of the catalase mimetic activity.
\end{abstract}

(c) 2016 Elsevier Ltd. All rights reserved.

\section{Introduction}

Some soda-lime-phosphosilicate glasses, such as Hench's Bioglass $45 \mathrm{~S} 5$, when in contact with the body fluids, form a layer of bone-like apatite on their surfaces which allows the connection between hard tissues (bone) and soft ones (collagens and muscles) [1]. The mechanism of formation of this apatite layer proposed by Hench is based on a long series of reactions occurring at the interface between the glass and the biological medium [2,3]. The degree of reactivity exhibited in the biological environment is related to the chemical composition of glasses [4]. In the last years, several ions have been added in the composition of bioactive glasses in order to introduce peculiar properties. For this reason, it is important to investigate with experimental and computational methods the structural role of the doped ions on the glass structure and reactivity. [5-10].

Very recently, we demonstrated that the introduction of small amounts of $\mathrm{CeO}_{2}$ to the Hench's Bioglass ${ }^{\circledR}$ confers antioxidant properties, such as catalase mimetic activity [11]. This enzyme catalyzes the decomposition of hydrogen peroxide $\left(\mathrm{H}_{2} \mathrm{O}_{2}\right)$ into water and oxygen, thus protecting cells from oxidative stress by reactive oxygen species

\footnotetext{
* Corresponding author.

E-mail address: gmalavasi@unimore.it (G. Malavasi).
}

(ROS) [12], such as hydrogen peroxide [13]. We showed that the ability of these glasses to present catalase mimetic activity is strictly related to the simultaneous presence of $\mathrm{Ce}^{3+}$ and $\mathrm{Ce}^{4+}$ on the glass surface, as it happens in $\mathrm{CeO}_{2}$ nanoparticles (CeNPs). In fact, the enzyme mimetic activity of $\mathrm{Ce}^{3+}$ and $\mathrm{Ce}^{4+}$-containing materials was demonstrated for the first time by means of CeNPs [14-19]. The authors showed that the amount of the $\mathrm{Ce}^{3+} / \mathrm{Ce}^{4+}$ ratio is strictly related to the biocatalytic mimetic activity exhibited by these nanoparticles; the relative concentration of $\mathrm{Ce}^{3+}$ and $\mathrm{Ce}^{4+}$ is mainly affected by the dimensions of the CeNPs [19-21], and the kinetic of redox conversion $\mathrm{Ce}^{3+} \leftrightarrow \mathrm{Ce}^{4+} \mathrm{de}-$ pends on the environment [22].

Moreover, Singh et al. [23] showed that the interaction of phosphate groups with $\mathrm{Ce}^{3+}$ ions present into the Ce NPs leads to the complete disappearance of Super Oxide Dismutase (SOD) activity and concomitant increase in catalase mimetic activity, concluding that a high surface concentration of $\mathrm{Ce}^{3+}$ oxidation state favors SOD mimetic activity, while materials with a high surface concentration of $\mathrm{Ce}^{4+}$ possess higher catalase mimetic activity.

Thus, a deep understanding of the structural role of phosphate as a component of the biomaterials and of the biological environments is required.

In our previous work [11], the catalase mimetic activity of Cecontaining bioactive glasses was investigated for a series of Ce-doped glasses based on the Hench composition in water solution. However, 
the antioxidant properties of these materials are strongly influenced by the composition of the solution in which they are tested, thus further investigations on their performance in the physiological medium is needed.

In particular, the aim of this work is to investigate the effect of the addition/presence of phosphate groups on the catalase mimetic activity of Ce-containing bioactive glasses with different compositions. Two series of Ce-containing potential bioactive glasses, one based on Hench's composition (where phosphate is present) and the second based on the P-free Kokubo's composition [24] have been synthesized and characterized by using Scanning Electron Microscopy (SEM), Differential Scanning Calorimetry, UV-vis, XRD, X-ray photoelectron spectroscopy (XPS) and ICP Spectroscopy and Molecular Dynamics Simulations. Bioactivity tests have been performed in simulated body fluid solution (SBF) [25] whereas the catalase mimetic activity tests have been carried out in both water and SBF.

\section{Materials and methods}

\subsection{Synthesis of the glass samples}

Two series of bioactive glasses doped with variable percentages of cerium oxide have been synthesized via the melting method [11]. The parent glass of the first series, hereafter identified as $\mathrm{H}$ series, is the composition of the well-known 45S5 Bioglass ${ }^{\circledR}$, whereas the parent glass of the second one (hereafter referred as K series) is the phosphatefree glass proposed by Kokubo et al. [24]. The molar compositions of the samples discussed in this paper are reported in Table 1 . The samples were prepared by mixing reagent grade $\mathrm{SiO}_{2}, \mathrm{Na}_{2} \mathrm{CO}_{3}, \mathrm{CaCO}_{3}$, $\mathrm{Na}_{3} \mathrm{PO}_{4} \cdot 12 \mathrm{H}_{2} \mathrm{O}$ (only for $\mathrm{H}$ glass series), and $\mathrm{CeO}_{2}$ in an agate mortar. Then each batch was put into a Pt crucible, and melted in an electric oven. The heating ramp was set to $15^{\circ} \mathrm{C} / \mathrm{min}$ up to $1000{ }^{\circ} \mathrm{C}$ and $8{ }^{\circ} \mathrm{C} / \mathrm{min}$ up to $1350{ }^{\circ} \mathrm{C}$. Samples were maintained at this temperature for $2 \mathrm{~h}$, to ensure optimal melting and mixing of all the oxides, and finally quenched at room temperature on a graphite plate. The obtained glasses were homogeneous and transparent.

Attempts to synthesize $\mathrm{K} \_5.3$ (series $\mathrm{K}$ with $5.3 \%$ of $\mathrm{CeO}_{2}$ ) and $\mathrm{H} \_7.2$ (series $\mathrm{H}$ with $7.2 \%$ of $\mathrm{CeO}_{2}$ ) systems yield heterogeneous and opaque samples characteristic of partial crystallized materials. The glasses were milled in order to have diameters in the range $500-250 \mu \mathrm{m}$. The powder dimension was chosen in order to compare the present results with that obtained previously [11].

We heated each of the samples containing cerium to their crystallization temperature for $2 \mathrm{~h}$, and then we performed the X-ray diffraction (XRD) analyses over the crystallized samples.

\subsection{Characterization of the glasses}

The powder glass samples were characterized before and after soaking in solution. The sample before the soaking was indicated "as quenched (AQ)".

\subsubsection{UV-vis spectroscopy}

UV-vis absorption spectra on AQ and soaked powders were collected to gain qualitative information about the oxidation state of cerium in the glasses. We used the HP8452 UV-vis spectrometer equipped with

Table 1

Nominal composition in \%mol of the studied systems.

\begin{tabular}{lcccccccc}
\hline & K & K_1.2 & K_3.6 & K_5.3 & H & H_1.2 & H_3.6 & H_5.3 \\
\hline $\mathrm{CeO}_{2}$ & - & 1.2 & 3.6 & 5.3 & - & 1.2 & 3.6 & 5.3 \\
$\mathrm{SiO}_{2}$ & 50.0 & 49.4 & 48.2 & 47.4 & 46.2 & 45.6 & 44.6 & 43.8 \\
$\mathrm{Na}_{2} \mathrm{O}$ & 25.0 & 24.7 & 24.1 & 23.7 & 24.3 & 24.0 & 23.4 & 23.0 \\
$\mathrm{CaO}$ & 25.0 & 24.7 & 24.1 & 23.7 & 26.9 & 26.6 & 25.9 & 25.5 \\
$\mathrm{P}_{2} \mathrm{O}_{5}$ & - & - & - & & 2.6 & 2.6 & 2.5 & 2.4
\end{tabular}

the diffuse reflectance sphere, and we collected all the spectra in the range $200-850 \mathrm{~nm}$, using $\mathrm{BaSO}_{4}$ as reference.

\subsubsection{Differential Thermal Analysis (DTA)}

Differential thermal analyses were performed over the AQ glasses to obtain the values of their melting points and their crystallization temperatures $\left(\mathrm{T}_{\mathrm{c}}\right)$. We weighted $\sim 30 \mathrm{mg}$ of powders in a platinum crucible and performed the analysis in air. We set the scan rate at $10{ }^{\circ} \mathrm{C} / \mathrm{min}$, for a range between $20^{\circ}$ and $1200^{\circ} \mathrm{C}$.

\subsubsection{X-ray diffraction $(X R D)$}

XRD measurements were carried out over the AQ and the soaked glasses. We analyzed all the specimens in the $(2 \theta) 10^{\circ}-55^{\circ}$ range employing an X'Pert PRO - PANAnalytical apparatus, equipped with Ni-filtered $\mathrm{Cu} K \alpha$ radiation $(\lambda=1.54060 \AA)$.

\subsubsection{Infrared spectroscopy (IR)}

The IR spectra were collected for the AQ and the soaked glasses in the range $400-4000 \mathrm{~cm}^{-1}$ by using a FT-IR Perkin Elmer 1600 spectrometer. We performed the measurements over pellets prepared with $1 \mathrm{mg}$ of glass and $100 \mathrm{mg}$ of $\mathrm{KBr}$.

\subsubsection{X-ray photoelectron spectroscopy (XPS)}

XPS was used to obtain quantitative information on the relative concentration of $\mathrm{Ce}^{3+}$ and $\mathrm{Ce}^{4+}$ ions on the surface of the AQ samples. The spectra were measured using $\mathrm{Al} \mathrm{K}_{\alpha}$ photons as the exciting probe. The Ce $3 \mathrm{~d}$ photoemission spectra were fitted using a Shirley-type background and five spin-orbit split doublets, three related to $\mathrm{Ce}^{4+}$ ionic species, and two related to $\mathrm{Ce}^{3+}$ ionic species, following previous works $[26,27]$. The free parameters in the fitting were the areas of the peaks, while the shifts in binding energy position and the Lorentzian/ Gaussian width of the individual components were fixed to the values used in reference [11]. The $\mathrm{Ce}^{3+}$ and $\mathrm{Ce}^{4+}$ relative concentrations were obtained from the relative weight of the area of the peaks related to each ionic species. The absolute values of the $\mathrm{Ce}^{3+}$ and $\mathrm{Ce}^{4+}$ relative concentrations evaluated in this way are approximate; however, their variation among the glass series may be considered reliable.

\subsubsection{Molecular dynamic (MD) simulations}

Since the H series was already characterized in a previous work [28] we have here generated structural models of the K series, only. Classical MD simulations of the K, K_1.2 and K_3.6 glasses were performed by means of the DL_POLY® 2.14 package [29] employing a wellestablished melt-quench computational protocol [30].

In this approach, an initial random configuration containing about 10,000 atoms enclosed in a periodic cubic box is melted at $3200 \mathrm{~K}$ for $100 \mathrm{ps}$ and then cooled down to $300 \mathrm{~K}$ at a nominal cooling rate of $5 \mathrm{~K} \mathrm{ps}^{-1}$. The resulting glass structures have been subjected to a final NVT trajectory of $70 \mathrm{ps}$; the structural analysis was performed on 501 configurations sampled at regular intervals during the last 50 ps of MD trajectory. The box sides (reported in Table S1 of the ESI) were set accordingly to densities calculated with the Priven empirical method [31] (Table S1, ESI), which is encoded in the Sciglass package [32].

Because of the employment of non-experimental densities, the final glass models were relaxed for $0.2 \mathrm{~ns}$, at $300 \mathrm{~K}$ and atmospheric pressure using the Berendsen NPT ensemble to check whether significant volume variations occurred after the relaxations. All boxes slightly expanded and for all of them the volume variations were comprised between 0.72 and $1.65 \%$. The $\mathrm{Ce}^{3+} / \mathrm{Ce}^{4+}$ ratio of each glass composition was fixed accordingly to experimental findings. The interatomic forces acting between the constituting ions have been described by using a shell model force field able to accurately reproduce the short and medium range structure of multicomponent oxide glasses [28,33-39]. In this model, cations are represented by rigid points bearing full formal charges $\left(\mathrm{Si}^{4+}, \mathrm{Ca}^{2+}, \mathrm{Ce}^{3+}, \mathrm{Ce}^{4+}, \mathrm{Na}^{+}\right)$, whereas anions are split in a shell of charge $-Y$ and a massive core of charge $Z(Z+Y$ is the total atomic 
charge; -2 for $\mathrm{O}$ ions), which are coupled adiabatically by a harmonic spring potential [24]. The oxygen shell interacts with the $\mathrm{Si}^{4+}, \mathrm{Ce}^{3+}$, $\mathrm{Ce}^{4+}, \mathrm{Ca}^{2+}$ and $\mathrm{Na}^{+}$cations through a Buckingham term, and Coulomb forces act between all species bearing a formal charge, in the Born Mayer model. Three-body screened harmonic potentials have been employed to control the $\mathrm{O}-\mathrm{Si}-\mathrm{O}$ angle, to guide tetrahedral coordination. Therefore, in the shell model, the polarizability of oxygen is straightforwardly included, and it is also environment dependent due to the forces acting on the oxygen shell by the other ions. This allows for a better glass structure relaxation during quenching and leads to glasses with improved medium-range structures with respect to those generated by using the rigid ion model [40]. A detailed description of the force-field functional forms as well as the complete list of parameters is reported in refs. [28,33,34].

\subsection{Catalase mimetic activity tests}

The samples were soaked (under continuous stirring) in a $1 \mathrm{M}$ solution of $\mathrm{H}_{2} \mathrm{O}_{2}$ for $24 \mathrm{~h}, 96 \mathrm{~h}$, and $168 \mathrm{~h}$. A constant glass mass/volume of solution ratio of $5 \mathrm{mg} / \mathrm{mL}$ was kept. The same tests were also performed in a solution $1 \mathrm{M}$ of hydrogen peroxide in simulated body fluid (SBF). The SBF solution was prepared through the method explained in Ref. [25]. After the soaking, we filtered the solutions, we measured the $\mathrm{pH}$ value and we determined the residual $\mathrm{H}_{2} \mathrm{O}_{2}$ through titration with $\mathrm{KMnO}_{4}$. The reacted powders were dried in oven at $60{ }^{\circ} \mathrm{C}$ overnight, and characterized again after the treatment.

\subsubsection{ICP-OES analyses}

To quantify the release of the different ions in solution during the reaction we analyzed the SBF solutions before and after the contact with the glasses with the ICP-OES Perkin Elmer Optima 4200DV, equipped with ultrasonic nebulizer CETAC.

\subsection{Bioactivity tests}

The bioactivity tests in SBF were performed with the method explained in Ref. [25]. We soaked $150 \mathrm{mg}$ of powder samples in $100 \mathrm{~mL}$ of SBF for 7, 14, 21 and 28 days and then, we filtered the solutions, washed the glass powders with acetone and analyzed the solids with the FT-IR and the XRD to evaluate the formation of hydroxyl-apatite on the surface of the samples.

\subsubsection{Environmental Scanning Electron Microscopy-Energy Dispersive Spectroscopy (ESEM-EDS)}

After the soaking in SBF, we collected images of the reacted glasses to gain a morphological and elemental characterization of the surfaces and to determine if there were detectable apatite-like areas. The morphological and elemental analyses of the solid products were carried out by means of Environmental Scanning Electron Microscopy-Energy Dispersive Spectroscopy using a FEI Quanta 200 instrument (Fei Company, The Netherlands), equipped with an INCA 350 EDS apparatus (Oxford Instruments, UK); EDS analysis was performed over different areas of the sample and the maximum value of $\sigma$ was $0.5 \%$.

\section{Results}

A full characterization of the $\mathrm{K}$ series of glasses, here investigated for the first time, is reported. For the $\mathrm{H}$ series of glasses the catalase mimetic activity tests in $\mathrm{H}_{2} \mathrm{O}_{2}+\mathrm{SBF}$ and the characterizations performed after soaking are carried out and discussed for the first time, whereas the results of bioactivity, [41] and catalase mimetic activity in water [11], have been reported previously and are here considered for comparison purposes.

\subsection{Characterization of the K series of glasses}

\subsubsection{UV-vis spectroscopy}

Fig. 1a reports the UV-vis spectra of the $\mathrm{K}$ series of AQ glasses, together with the spectra of $\mathrm{CeO}_{2}$ and $\mathrm{Ce}\left(\mathrm{NO}_{3}\right)_{3} \cdot 6 \mathrm{H}_{2} \mathrm{O}$, as reference for $\mathrm{Ce}^{4+}$ and $\mathrm{Ce}^{3+}$ respectively. The $\mathrm{K}$ sample shows a weak band around $300 \mathrm{~nm}$, consistent with the UV-vis signal of the soda-lime-silicate glasses [42]. The doped samples show different spectra, with a strong absorption band between 350 and $400 \mathrm{~nm}$, and a second weak band around $220 \mathrm{~nm}$. Following the literature [43,44], we could assign the first signal to the charge transfer (CT) $\mathrm{O}^{2-}{ }_{2 \mathrm{p}}-\mathrm{Ce}^{4+}{ }_{4 \mathrm{p}}$ transition and the second one to the electronic transition $4 \mathrm{f}^{1}-5 \mathrm{~d}^{1}$ of $\mathrm{Ce}^{3+}$. In addition, the shoulder between 500 and $600 \mathrm{~nm}$ can be assigned to the $\mathrm{CT} \mathrm{Ce}^{3+}$ $\mathrm{Ce}^{4+}$ transition [45]. Fig. $1 \mathrm{~b}$ reports the spectra collected for the AQ samples of H_3.6 and K_3.6. It is possible to notice that at high $\lambda$ (above $400 \mathrm{~nm}$ ), the absorption is slightly higher for the K_3.6 sample. As previously proposed $[28,40]$ this effect could be attributed to an increment in the content of $\mathrm{Ce}^{4+}$ with respect to $\mathrm{Ce}^{3+}$. Thus, we can assert that in the $\mathrm{K} \_3.6$ glass there is a major content of $\mathrm{Ce}^{4+}$ with respect to the $\mathrm{H} \_3.6$ glass, even if the content of $\mathrm{CeO}_{2}$ is the same. The difference in the UV region (200-400 nm) between the H_3.6 and K_3.6 glasses is probably due to the phosphate groups present only in the $\mathrm{H}_{-} 3.6$ sample. In fact, the band at around $300 \mathrm{~nm}$ is due to $\mathrm{Si}-\mathrm{O}-(\mathrm{Si}, \mathrm{Ca})$ absorption characteristic of silicate glasses, whereas the absorption at $250 \mathrm{~nm}$ is due to the $\mathrm{P}-\mathrm{O}-(\mathrm{P}, \mathrm{Ca})$ groups [46]. In order to confirm this finding, the UV-vis absorption spectra of the $\mathrm{H}$ and the K glasses have been reported in Figure S1 of the ESI. The figure shows that the band centered at $250 \mathrm{~nm}$ in the $\mathrm{H}$ glass is not observed in the K glass.
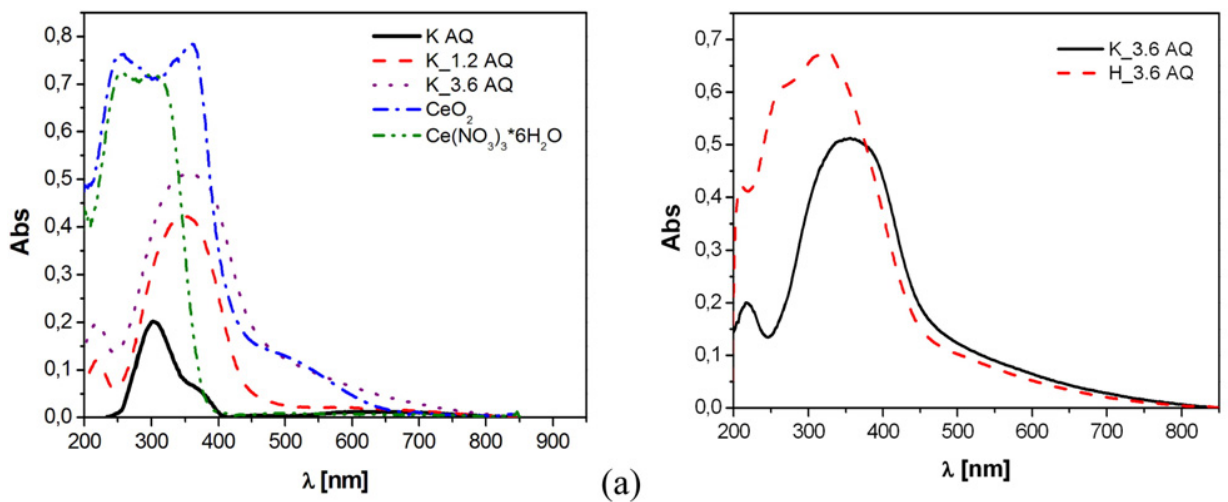

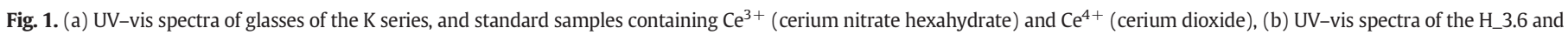
K_3.6 glasses. 


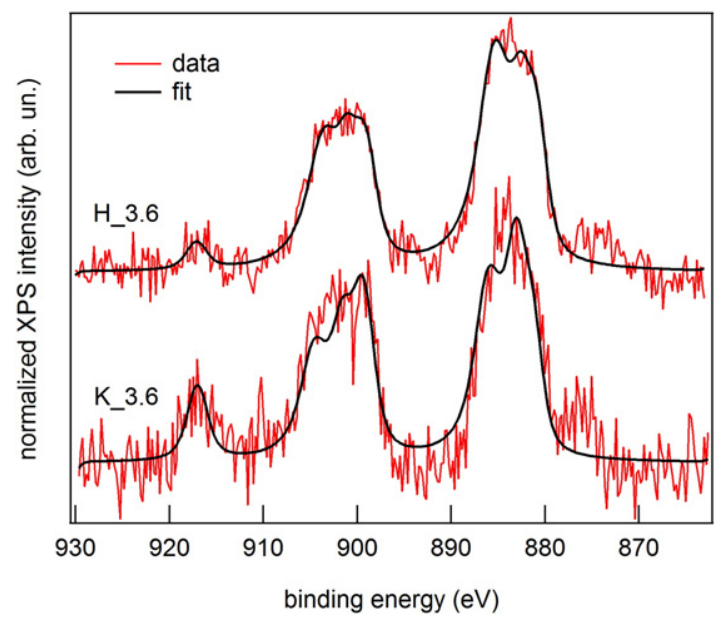

Fig. 2. Ce 3d XPS spectra for the H_3.6 and K_3.6 samples (red lines) after Shirley-type background subtraction, and corresponding fits (black lines).

\subsubsection{X-ray photoelectron spectroscopy (XPS)}

Fig. 2 reports the Ce 3d XPS peaks of the H_3.6 [11] and K_3.6 samples and the fittings obtained using the procedure described in the experimental section. In spite of the low signal to noise ratio, due to the low Ce concentration in the samples, some differences in the spectra of the two samples can be appreciated. In particular, the intensity of the band around $917 \mathrm{eV}$, related to $\mathrm{Ce}^{4+}$ ions only, is much higher in the $\mathrm{K}$ sample spectrum. The $\mathrm{Ce}^{4+}$ relative concentrations, evaluated from the fitting of the Ce $3 \mathrm{~d}$ peaks, with the procedures outlined in the experimental section, are $26 \pm 5 \%$ [11] for the H_3.6 and $46 \pm 5 \%$ for the K_3.6 sample, and confirm the higher relative $\mathrm{Ce}^{4+}$ concentration in K samples observed qualitatively by UV-vis spectroscopy.

\subsubsection{Differential Thermal Analysis (DTA)}

Fig. 3a reports the results of the DTA analysis performed over the $K_{-} \_1.2$ and the $K_{-}$3.6. We found that $T_{c}$ increases as the Ce content increases, indeed for the $\mathrm{K}$ sample the $\mathrm{T}_{\mathrm{c}}$ is $661^{\circ} \mathrm{C}$, as reported in Ref. [47], for $\mathrm{K}_{-} 1.2$ it is $672{ }^{\circ} \mathrm{C}$ and for $\mathrm{K} \_3.6$ it is $685^{\circ} \mathrm{C}$. A similar trend of $\mathrm{T}_{\mathrm{C}}$ was also detected for the $\mathrm{H}$ series, in fact the value increase from $724{ }^{\circ} \mathrm{C}$ for the $\mathrm{H}$ glass to $735^{\circ}, 749^{\circ} \mathrm{C}$ for $\mathrm{H}_{-} 1.2$ and $\mathrm{H} \_3.6$, respectively. However, the glass with the maximum $\mathrm{CeO}_{2}$ content, $\mathrm{H}_{-} 5.3$, showed a slightly decrease of $\mathrm{T}_{\mathrm{c}}$ to $738^{\circ} \mathrm{C}$ (Fig. 3b).

\subsubsection{X-ray diffraction (XRD)}

The results of XRD analyses are shown in Fig. 4. As already reported by Lusvardi et al. [47] in a previous investigation, the XRD analysis performed after thermal treatment at $661{ }^{\circ} \mathrm{C}$ of the $\mathrm{K}$ glass reveals that the $\mathrm{Na}_{2} \mathrm{CaSi}_{2} \mathrm{O}_{6}$ phase crystallizes from the glass. The presence of cerium does not affect the crystallization process; in fact, the $\mathrm{Na}_{2} \mathrm{CaSi}_{2} \mathrm{O}_{6}$ cyclosilicate (JCPDS 77-2189) is the principal crystal phase observed in both the K_1.2 and K_3.6 crystallized glasses. For sake of clarity, only the three principal peaks: $2 \theta=33.5^{\circ}, 2 \theta=34.0^{\circ}$ and $2 \theta=48.5^{\circ}$ are highlighted in Fig. 4. In addition, a weak signal at $28.5^{\circ}$ characteristic of $\mathrm{CeO}_{2}$ (JCPDS 34-0394) can be observed in the K_3.6 sample. The same signal is not present in the spectra of K_1.2 probably because of the small amount of cerium, and it is present together with the others two most intense peaks of the $\mathrm{CeO}_{2}$ in the AQ K_5.3 glasses. The same analysis performed on the $\mathrm{H}$ series [11] revealed the presence of $\mathrm{CeO}_{2}$ in the H_1.2, and H_3.6 systems; the intensity of the peak attributed to $\mathrm{CeO}_{2}$ is more intense with respect to that detected for $\mathrm{K} \_3.6$ system. This experimental evidence highlights that in the P-containing systems (H series) the presence of phosphorous enhances the $\mathrm{Ce}-\mathrm{Ce}$ clustering inside the glass network. However, the presence of $\mathrm{PO}_{4}$ groups favors the crystallization in $\mathrm{H}_{-} 3.6$ and $\mathrm{H} \_5.3$ systems of the $\mathrm{CePO}_{4}$ phase. This suggests that in the $\mathrm{H}$ series the Ce ions are also surrounded by phosphate groups and form Ce-phosphate rich zones in the glass network.

\subsubsection{Molecular dynamics simulations}

The structural models generated by means of classical molecular dynamics simulations were analyzed in details in order to shed some lights on the short and medium range order of the $\mathrm{K}$ glass series as a function of the $\mathrm{CeO}_{2}$ content and to compare them with those obtained for the $\mathrm{H}$ series. Table 2 reports the average $\mathrm{X}-\mathrm{O}$ coordination numbers (where $\mathrm{X}=\mathrm{Si}, \mathrm{Ce}^{3+/ 4+}$, Ca and $\mathrm{Na}$ ). As expected, silicon ions are fourcoordinated, and their coordination numbers are not influenced by the addition of Ce ions.

$\mathrm{Ce}^{3+}$ ions are coordinated by about 6.3-6.4 NBOs whereas $\mathrm{Ce}^{4+}$ ions by 6.7-6.8 NBOs and their coordination numbers (CNs) do not significantly change with $\mathrm{CeO}_{2}$ content. These values are slightly smaller than those found in Ce-containing bioactive glasses of the Hench's family of about $0.2-0.3$ NBOs but are still in good agreement with the values obtained in previous MD investigations $[28,48,49]$ and EXAFS and X-ray diffraction measurements [50-52] on phosphate glasses. These findings together with the observation that only NBOs are coordinated to Ce ions suggest that Ce first coordination shell does not drastically change with glass composition if a proper number of NBOs is present in the glass structure.
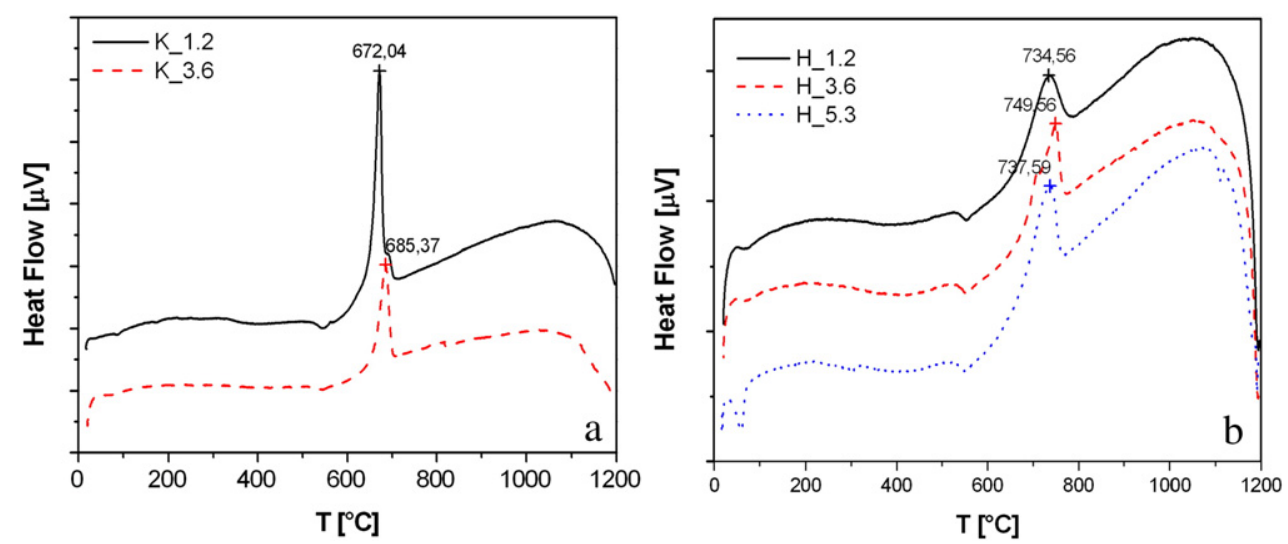

Fig. 3. DTA plots of (a) K_1.2 and K_3.6 glasses and (b) Ce-containing glasses of the H series. 


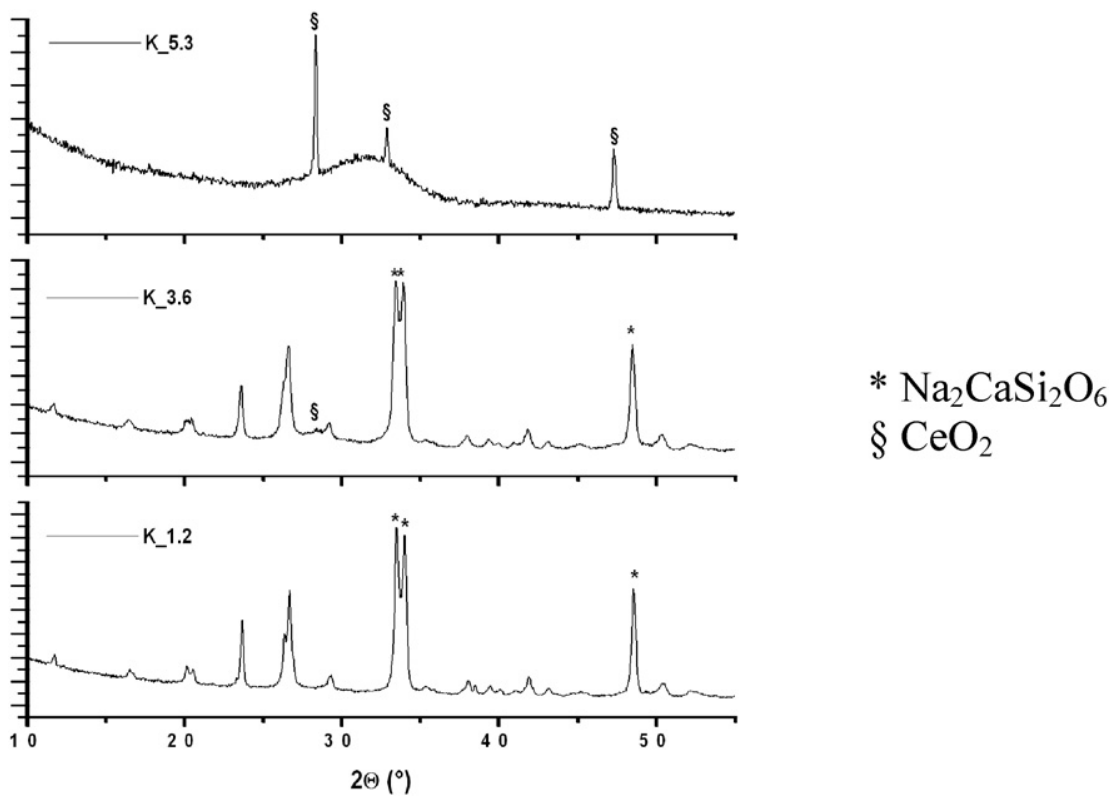

Fig. 4. XRD spectra of the K_1.2 and K_3.6 glasses after crystallization at $672{ }^{\circ} \mathrm{C}$ and $685{ }^{\circ} \mathrm{C}$ respectively, and of the K_5.3 AQ.

As for the $\mathrm{Na}$ and $\mathrm{Ca}$ ions, their $\mathrm{CN}$ are in agreement with previous MD and NMR investigations on silicate glasses [53-56]. The $\mathrm{CN}$ of $\mathrm{Na}$ slightly increases from 5.6 to 5.8, whereas that of Ca increases from 5.5 to 5.7 with the addition of $\mathrm{CeO}_{2}$. It is interesting to note that the number of NBOs and bridging oxygen (BOs) atoms coordinated to Ca remains essentially constant in the four compositions analyzed, whereas a depletion of BO and an increment of NBO are observed around Na cations upon $\mathrm{CeO}_{2}$ addition. These are the same trends previously observed in the $\mathrm{H}$ series [11].

To investigate the effect of $\mathrm{CeO}_{2}$ on the glass polymerization, the $\mathrm{Q}^{\mathrm{n}}$ distributions $\left(\mathrm{Q}^{\mathrm{n}}\right.$ stands for 4-coordinated network former ion bonded to $\mathrm{n}$ bridging oxygens) of Si for the K, K_1.2, K_3.6, and K_5.3 glasses are listed in Table 3.

The un-doped K glass presents a trinomial $\mathrm{Q}^{\mathrm{n}}(\mathrm{Si})$ distribution dominated by $\mathrm{Q}^{2}$ species (55.7\%) with a similar population of $\mathrm{Q}^{1}$ and $\mathrm{Q}^{3}$

Table 2

Average $\mathrm{X}-\mathrm{O}$ coordination numbers $\left(\mathrm{X}=\mathrm{Si}, \mathrm{Ce}^{3+/ 4+}, \mathrm{Ca}, \mathrm{Na}\right)$.

\begin{tabular}{lcccc}
\hline $\mathrm{CN}_{\mathrm{X}-\mathrm{O}}$ & $\mathrm{K}$ & K_1.2 & K_3.6 & K_5.3 \\
\hline $\mathrm{Si}-\mathrm{O}$ & 4.0 & 4.0 & 4.0 & 4.0 \\
$\mathrm{Ca}-\mathrm{O}$ & 5.5 & 5.6 & 5.7 & 5.6 \\
$\mathrm{Ca}-\mathrm{BO}$ & 0.5 & 0.5 & 0.5 & 0.4 \\
$\mathrm{Ca}-\mathrm{NBO}$ & 5.1 & 5.1 & 5.2 & 5.2 \\
$\mathrm{Na}-\mathrm{O}$ & 5.6 & 5.6 & 5.8 & 5.8 \\
$\mathrm{Na}-\mathrm{BO}$ & 1.4 & 1.4 & 1.3 & 1.2 \\
$\mathrm{Na}-\mathrm{NBO}$ & 4.2 & 4.3 & 4.5 & 4.6 \\
$\mathrm{Ce}(\mathrm{III})-\mathrm{O}^{*}$ & - & 6.4 & 6.3 & 6.3 \\
$\mathrm{Ce}(\mathrm{IV})-\mathrm{O}^{*}$ & - & 6.8 & 6.8 & 6.7 \\
\hline
\end{tabular}

* Cerium ions are coordinated by NBO only.

Table 3

$\mathrm{Q}^{\mathrm{n}}$ distributions (pop\%) and network connectivity (NC) of Si network former calculated by MD simulations.

\begin{tabular}{lcccccc}
\hline & $\mathrm{n}=0$ & $\mathrm{n}=1$ & $\mathrm{n}=2$ & $\mathrm{n}=3$ & $\mathrm{n}=4$ & $\mathrm{NC}$ \\
\hline K & 1.0 & 21.2 & 55.7 & 21.1 & 1.1 & 2.4 \\
K_1.2 & 1.2 & 26.5 & 52.2 & 18.8 & 1.2 & 1.9 \\
K_3.6 & 3.1 & 33.4 & 49.6 & 13.3 & 0.7 & 1.8 \\
K_5.3 & 5.1 & 40.2 & 43.6 & 10.8 & 0.4 & 1.6
\end{tabular}

species (21.2\%). By adding $\mathrm{CeO}_{2}$, the population of $\mathrm{Q}^{2}$ species drastically decreases to $43.6 \%$ (for $K$ _5.3Ce glass) whereas $Q^{1}$ increases to about $40 \%$ and $Q^{3}$ decreases to $10.8 \%$.

Therefore, the addition of $\mathrm{CeO}_{2}$ leads to a more fragmented network with the network connectivity (NC) monotonically decreasing from 2.4 for the K glass to 1.6 for K_5.3 glass. At constant content of $\mathrm{CeO}_{2}$, the glass polymerization is more pronounced for the $\mathrm{K}$ series than the $\mathrm{H}$ one for which the NC decreases from 2.1 (H glass) to 1.7 (H_5.3 glass) [11].

The more marked influence exerted by Ce ions in the NC of K glass series is due to the absence of phosphate groups which are able to donate NBO to Ce ions, indeed, in the K series the number of NBOs necessary to stabilize the first coordination sphere of Ce ions can only be supplied from the silicate depolymerization.

To gain insights on the medium range order and on the cations distributions in these glasses the cation - cation coordination numbers $\left(\mathrm{CN}_{\mathrm{X}-\mathrm{Y}}\right)$ have been computed by integrating the first peak of the corresponding pair distribution functions, and reported in Table 4 .

In previous investigation [11] we observed that the addition of $\mathrm{CeO}_{2}$ oxide in the $\mathrm{H}$ glass series caused an increment in the number of $\mathrm{Na}$ ions in the second coordination sphere of $\mathrm{Si}$ : from 4.5, for $\mathrm{H}$ glass, to 5.9 for $\mathrm{H} \_$5.3. At the same time, the number of Na surrounding P decreases from 6.0, for $\mathrm{H}$, to about 5.4-5.7 for Ce-containing compositions, whereas the number of $\mathrm{Ca}$ ions around $\mathrm{Si}$ and $\mathrm{P}$ cations was observed to be less dependent on the addition of $\mathrm{CeO}_{2}$. These data revealed that $\mathrm{Ce}$ ions tend to satisfy their coordination requirements by using NBO coming from the orthophosphate units. Table 4 shows that a different

Table 4

Average cation-cation coordination numbers.

\begin{tabular}{lcccc}
\hline $\mathrm{CN}_{\mathrm{X}-\mathrm{Y}}$ & $\mathrm{K}$ & K_1.2 & K_3.6 & K_5.3 \\
\hline $\mathrm{Si}-\mathrm{Na}$ & 6.7 & 6.6 & 6.5 & 6.3 \\
$\mathrm{Si}-\mathrm{Ca}$ & 3.5 & 3.4 & 3.4 & 3.3 \\
$\mathrm{Ce}{ }^{3+}-\mathrm{Si}$ & - & 7.0 & 7.1 & 6.9 \\
$\mathrm{Ce}^{4+}-\mathrm{Si}$ & - & 7.8 & 7.4 & 7.1 \\
$\mathrm{Ce}^{3+}-\mathrm{Ca}$ & - & 2.2 & 2.5 & 2.5 \\
$\mathrm{Ce}^{4+}-\mathrm{Ca}$ & - & 2.3 & 2.2 & 2.3 \\
$\mathrm{Ce}^{3+}-\mathrm{Na}$ & - & 6.8 & 6.4 & 6.4 \\
$\mathrm{Ce}^{4+}-\mathrm{Na}$ & - & 6.3 & 6.2 & 6.5 \\
\hline
\end{tabular}


Table 5

Average $\mathrm{Ca} / \mathrm{Na}$ ratio in the glass and $\mathrm{Ca} / \mathrm{Na}$ ratio around $\mathrm{Si}, \mathrm{Ce}(\mathrm{III})$ and $\mathrm{Ce}(\mathrm{IV})$ ions.

\begin{tabular}{lcccc}
\hline & K & K_1.2 & K_3.6 & K_5.3 \\
\hline $\mathrm{Ca} / \mathrm{Na}$ & 0.50 & 0.50 & 0.50 & 0.50 \\
$(\mathrm{Ca} / \mathrm{Na})_{\mathrm{Si}}$ & 0.52 & 0.51 & 0.52 & 0.53 \\
$(\mathrm{Ca} / \mathrm{Na})_{\mathrm{Ce} 3+}$ & - & 0.32 & 0.39 & 0.39 \\
$(\mathrm{Ca} / \mathrm{Na})_{\mathrm{C} 4+}$ & - & 0.37 & 0.35 & 0.35 \\
\hline
\end{tabular}

phenomenon occurs in the K series. In fact, the number of Na ions in the second coordination sphere of the $\mathrm{Si}$ ions decreases from 6.7 (K glass) to 6.3 (K_5.3 glass), whereas the number of Ca ions around Si decreases from 3.5 to 3.3 .

At the same time the number of $\mathrm{Si}$ ions around $\mathrm{Ce}(\mathrm{III})$ and $\mathrm{Ce}(\mathrm{IV})$ ions decreases from 7.0 to 6.9 and from 7.8 to 7.1 , respectively. The number of $\mathrm{Ca}$ ions around $\mathrm{Ce}$ (III) increases from 2.2 to 2.5, while it remains constant around $\mathrm{Ce}(\mathrm{IV})$. The number of $\mathrm{Na}$ ions around $\mathrm{Ce}(\mathrm{III})$ ions decreases from 6.8 to 6.4 , whereas it increases from 6.3 to 6.5 around $\mathrm{Ce}(\mathrm{IV})$.

This reveals that by adding $\mathrm{CeO}_{2}$, $\mathrm{Na}$ ions tend to migrate towards $\mathrm{Ce}(\mathrm{IV})$, whereas Ca ions towards Ce(III).

To investigate further which modifier among $\mathrm{Ca}$ and Na surrounds preferentially silicon and cerium ions we have computed the ratio between the number of $\mathrm{Ca}$ and $\mathrm{Na}$ in the second coordination sphere of $\mathrm{Si}, \mathrm{Ce}$ (III) and $\mathrm{Ce}(\mathrm{IV})$ ions and compared it to the $\mathrm{Ca} / \mathrm{Na}$ ratio in the nominal glass composition (which is 0.5 ). If the ratio is higher than 0.5 the cation is preferentially surrounded by Ca ions, whereas the contrary is true when the ratio is smaller than 0.5 . The values reported in the Table 5 reveal that silicon has similar preference towards $\mathrm{Ca}$ and $\mathrm{Na}$, whereas Ce ions tend to be surrounded by Na ions forming zones richer in $\mathrm{Ce}$ and $\mathrm{Na}$.

\subsection{Catalase mimetic activity tests}

\subsection{1. $\mathrm{H}_{2} \mathrm{O}_{2}$ degradation}

Fig. 5 reports the results of the titrations of the solutions after the soaking of the glasses for different times. It is possible to notice that for all the solutions the degradation of hydrogen peroxide is ceriumdependent, increasing as cerium content increases. Furthermore, the degradation of $\mathrm{H}_{2} \mathrm{O}_{2}$ changes with the environment, being higher in water solution than in SBF solution. In particular, we found that for both the series the most doped samples (H_5.3 and K_3.6, respectively) degraded $35 \%$ of $\mathrm{H}_{2} \mathrm{O}_{2}$ after $168 \mathrm{~h}$ of soaking in the first solution, and only ca. $25 \%$ of $\mathrm{H}_{2} \mathrm{O}_{2}$ after the same time in SBF.

\subsection{2. $\mathrm{pH}$ measurements}

When the reactions take place in hydrogen peroxide, an important increment in the values of $\mathrm{pH}$ during time (from 5.45 to 9.76) is observed. This increment is due to the exchanging reactions between the alkali and the alkali-earth ions of the glass and the protons of the solution $[1,57]$. Instead, fluctuations in $\mathrm{pH}$ values are very limited (from 7 to 8.5) for both the series when the samples are soaked in hydrogen peroxide and SBF. This is an expected behavior when working with buffered solutions, as in this case.

\section{$\mathrm{H}$ series $\mathrm{H}_{2} \mathrm{O}_{2} 1 \mathrm{M}$}

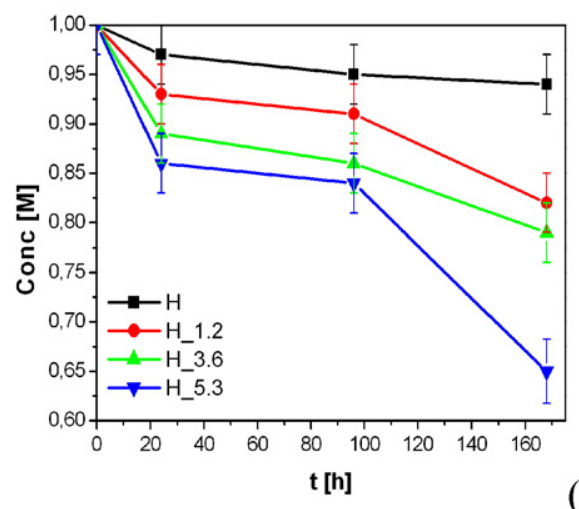

(a)

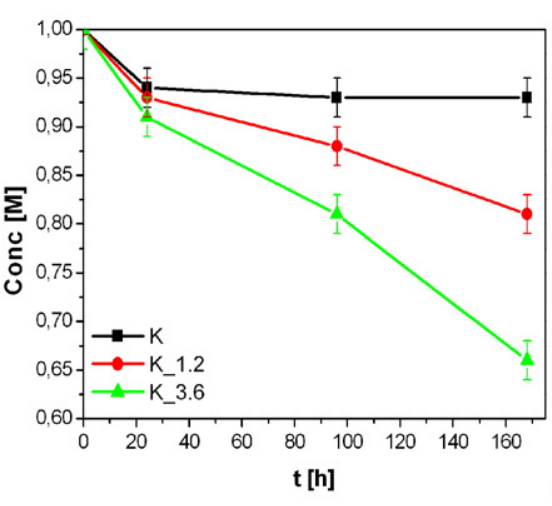

(c)

H series $\mathrm{H}_{2} \mathrm{O}_{2} 1 \mathrm{M}+\mathrm{SBF}$

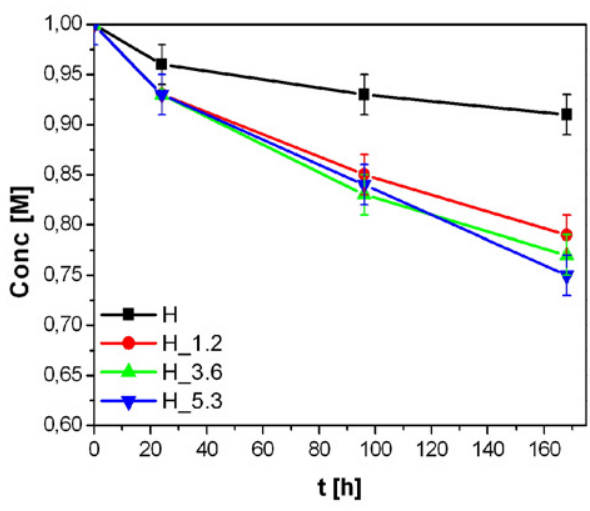

(b)

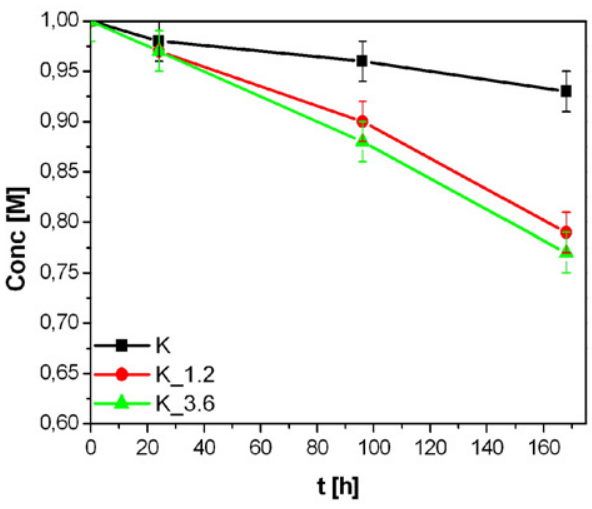

(d)

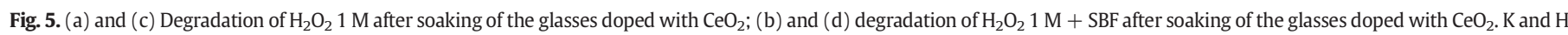
are reported as control. The lines serve only to guide the eyes. 

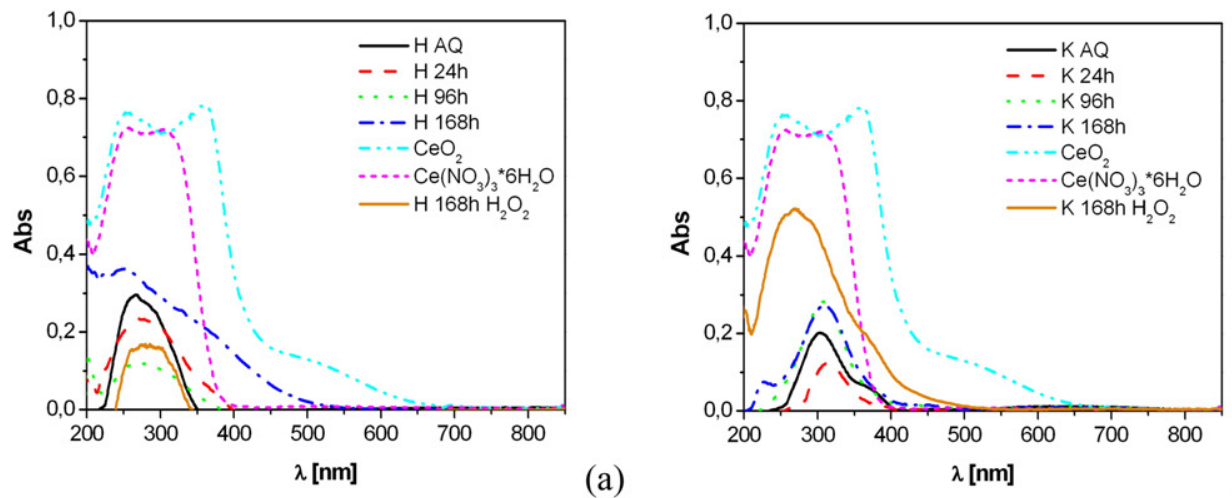

(b)
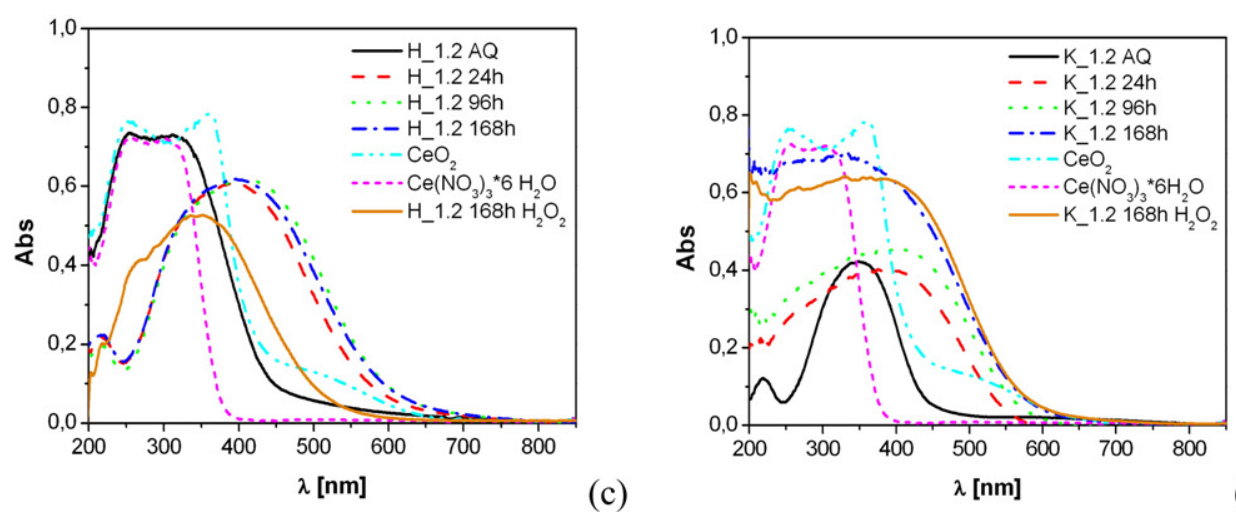

(d)
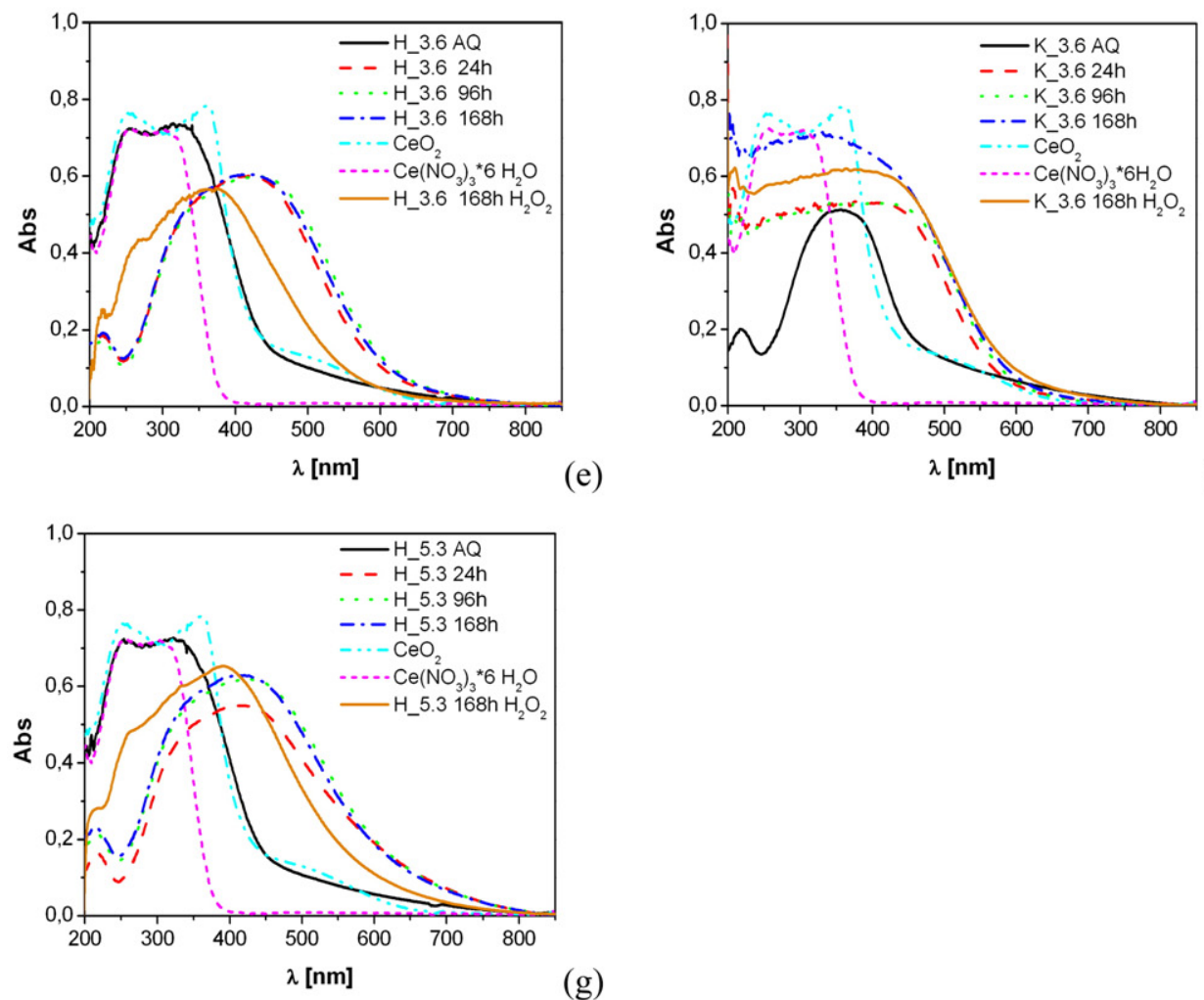

(f)

$(\mathrm{g})$

Fig. 6. UV-vis spectra of samples before (AQ) and after soaking in $1 \mathrm{M} \mathrm{H}_{2} \mathrm{O}_{2}+\mathrm{SBF}$ solution at different times: (a) $\mathrm{H}$ (b) $\mathrm{K}$ (c) $\mathrm{H} \_1.2$ (d) $\mathrm{K} \_1.2$ (e) $\mathrm{H} \_3.6$ (f) $\mathrm{K} \_3.6$ (g) $\mathrm{H} \_5.3$.

\subsubsection{UV-vis spectroscopy}

Fig. 6 shows the results of the UV-vis analyses over the reacted samples in $\mathrm{H}_{2} \mathrm{O}_{2}+\mathrm{SBF}$, as well as those of the AQ glasses and of $\mathrm{Ce}^{3+}$ and $\mathrm{Ce}^{4+}$ species reported as reference. It is possible to notice that for all the samples, regardless from the considered series, the absorption band shifts to higher $\lambda$ after $24 \mathrm{~h}$ of the soaking time, and then it remains unchanged for longer reaction time. This confirms, in qualitative manner, that the conversion of $\mathrm{Ce}^{3+}$ to $\mathrm{Ce}^{4+}$ takes place during the first 
a)

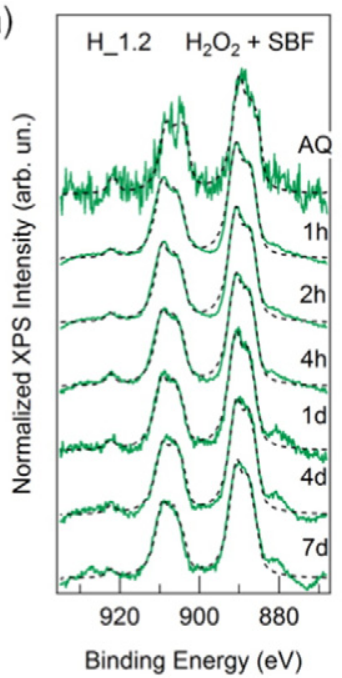

b)

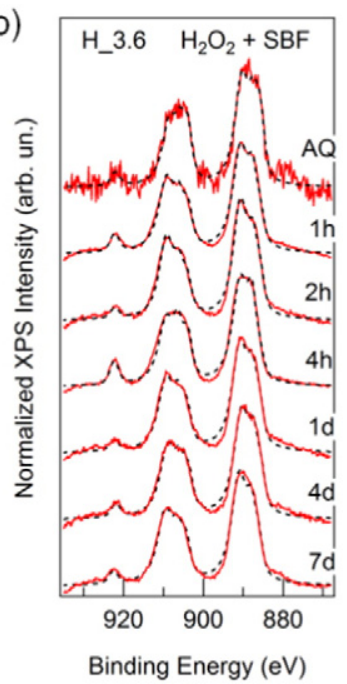

c)

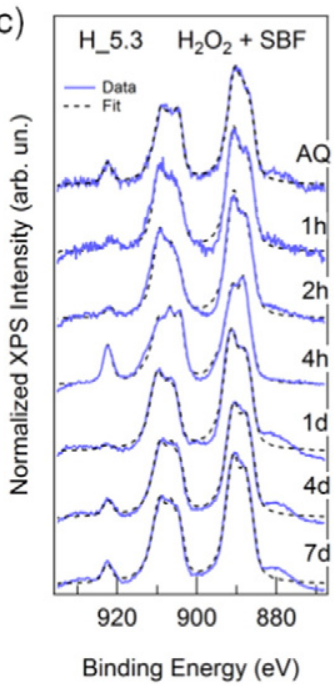

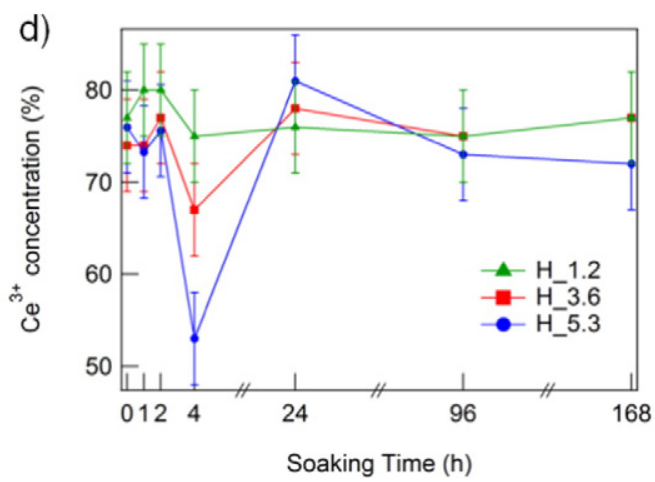

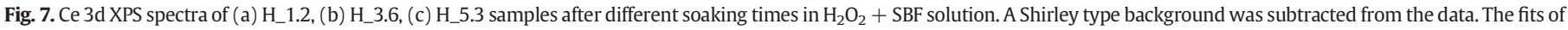
the spectra are also shown as a dashed line. (d) $\mathrm{Ce}^{3+}$ relative concentration evaluated from the fitting of $\mathrm{Ce} 3 \mathrm{~d}$ spectra.

$24 \mathrm{~h}$ of reaction with hydrogen peroxide for all samples (both for $\mathrm{H}$ and K series). [58,59].

\subsubsection{XPS analysis}

Ce 3d XPS spectra of the three $\mathrm{H}$ samples measured after different soaking times in $\mathrm{H}_{2} \mathrm{O}_{2}+\mathrm{SBF}$ solution are shown in Fig. 7. While sample $\mathrm{H}_{-} 1.2$ does not show significant changes of Ce $3 \mathrm{~d}$ peak shape as a function of soaking time, the spectra of the H_3.6 and H_5.3 samples are modified by soaking in the solution. In particular, as shown in Fig. 7 panel d), the $\mathrm{Ce}^{3+}$ relative concentration shows a significant decrease after $4 \mathrm{~h}$ soaking and a subsequent increase back to the original level. The decrease is more pronounced for the H_5.3 sample than for the H_3.6 one, i.e. when the cerium oxide concentration is higher. For the K series of glasses after soaking in SBF solution the Ce 3d XPS signal intensity is very small, probably due to the precipitation on the surface of insoluble phases. This hindered the possibility of obtaining reliable estimates of the $\mathrm{Ce}^{3+}$ and $\mathrm{Ce}^{4+}$ relative concentrations for these samples.

\subsubsection{ICP-OES analyses}

Table 6 lists the content of $\mathrm{Si}$, $\mathrm{Ca}$ and $\mathrm{P}$ ions of the $\mathrm{H}_{2} \mathrm{O}_{2}+\mathrm{SBF}$ solutions, before and after soaking of the $\mathrm{H}$ and $\mathrm{K}$ series. It is possible to notice that the trends for $\mathrm{Si}$ and $\mathrm{Ca}$ are the same for all the glasses: their concentrations increases with time. Instead, $\mathrm{P}$ behaves differently in the two series: it increases with time soaking in the $\mathrm{H}$ samples, while it decreases in the K series. The data collected with the ICP-OES suggest that the $\mathrm{H}$ series is a little bit more durable than the $\mathrm{K}$ series.
In particular, glasses of the K series release more Si with respect to the $\mathrm{H}$ series (Table 6). However, for both of them, the durability increases as the content of cerium increases. Cerium ions in solutions are under

Table 6

Amount of Si, Ca and P (expressed in ppm \pm std.dev.\%) released at different times of reaction.

\begin{tabular}{|c|c|c|c|c|}
\hline \multirow{2}{*}{ Time = } & & \multirow{2}{*}{$\frac{\mathrm{Si}[\mathrm{ppm}] \pm 5 \%}{0}$} & \multirow{2}{*}{$\frac{\mathrm{Ca}[\mathrm{ppm}] \pm 3 \%}{98}$} & \multirow{2}{*}{$\frac{\mathrm{P}[\mathrm{ppm}] \pm 5 \%}{34}$} \\
\hline & & & & \\
\hline \multirow{3}{*}{$\mathrm{H}$} & $24 \mathrm{~h}$ & 96 & 323 & 54 \\
\hline & $96 \mathrm{~h}$ & 115 & 519 & 67 \\
\hline & $168 \mathrm{~h}$ & 120 & 671 & 73 \\
\hline \multirow{3}{*}{ H_1.2 } & $24 \mathrm{~h}$ & 104 & 301 & 54 \\
\hline & $96 \mathrm{~h}$ & 115 & 422 & 61 \\
\hline & $168 \mathrm{~h}$ & 116 & 497 & 65 \\
\hline \multirow{3}{*}{ H_3.6 } & $24 \mathrm{~h}$ & 94 & 339 & 59 \\
\hline & $96 \mathrm{~h}$ & 101 & 356 & 44 \\
\hline & $168 \mathrm{~h}$ & 109 & 490 & 67 \\
\hline \multirow{3}{*}{ H_5.3 } & $24 \mathrm{~h}$ & 81 & 242 & 64 \\
\hline & $96 \mathrm{~h}$ & 90 & 268 & 53 \\
\hline & $168 \mathrm{~h}$ & 101 & 462 & 94 \\
\hline \multirow{3}{*}{$\mathrm{K}$} & $24 \mathrm{~h}$ & 90 & 379 & 36 \\
\hline & $96 \mathrm{~h}$ & 108 & 476 & 16 \\
\hline & $168 \mathrm{~h}$ & 138 & 1067 & 10 \\
\hline \multirow{3}{*}{ K_1.2 } & $24 \mathrm{~h}$ & 11 & 358 & 34 \\
\hline & $96 \mathrm{~h}$ & 124 & 498 & 17 \\
\hline & $168 \mathrm{~h}$ & 128 & 728 & 12 \\
\hline \multirow{3}{*}{ K_3.6 } & $24 \mathrm{~h}$ & 101 & 398 & 37 \\
\hline & $96 \mathrm{~h}$ & 111 & 380 & 24 \\
\hline & $168 \mathrm{~h}$ & 112 & 466 & 18 \\
\hline
\end{tabular}




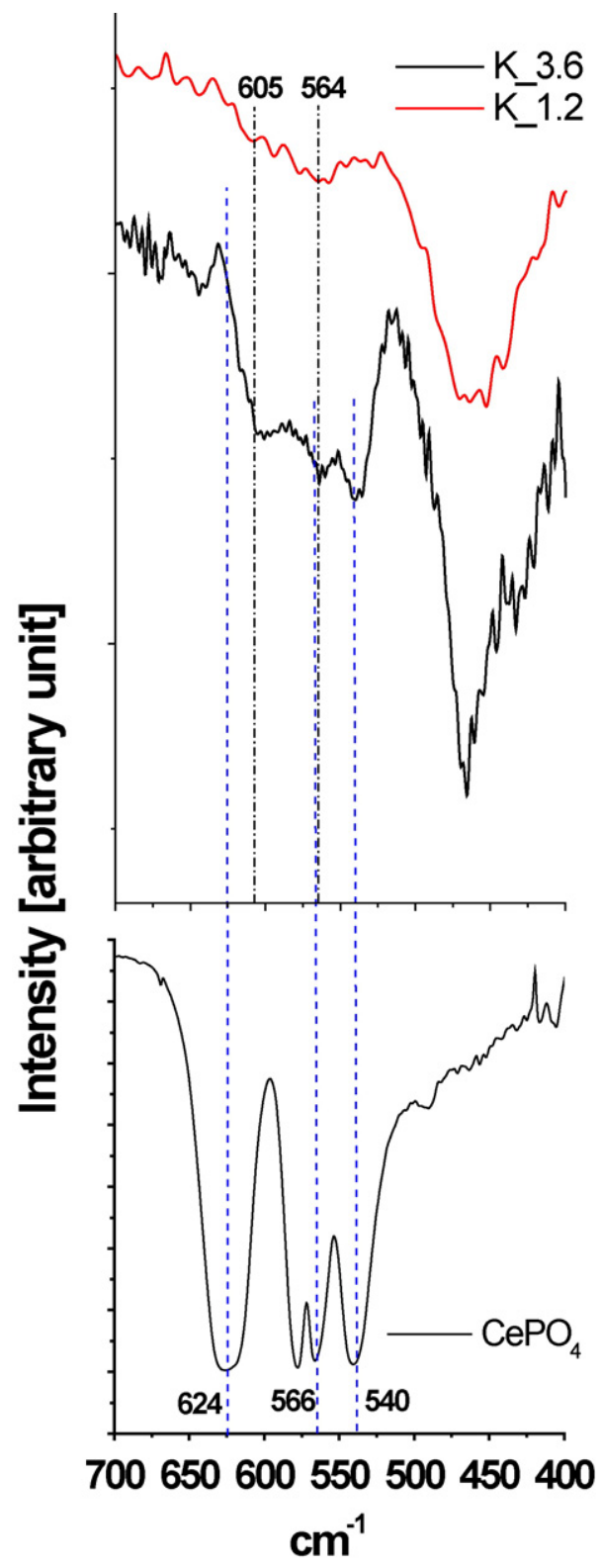

Fig. 8. IR spectra for the $\mathrm{K} \_1.2$ and $\mathrm{K} \_3.6$ samples after 28 days of treatment in $\mathrm{SBF} \cdot \mathrm{CePO}_{4}$ IR spectrum is reported as reference.

the detection limit for this element, thus their concentrations are assumed to be below $1 \mathrm{ppm}$ in each solution.

\subsection{Bioactivity tests}

\subsubsection{Infrared spectroscopy}

Fig. 8 shows the spectra of the FT-IR analyses for the K series after 28 days of soaking in SBF solution. The aim of this analysis is to investigate the range of the IR spectra between 700 and $400 \mathrm{~cm}^{-1}$ in order to verify the presence of the bands at 605 and $565 \mathrm{~cm}^{-1}$ that is usually assigned to apatite-like crystalline phase [60]. The K_1.2 and K_3.6 sample after 28 days of soaking in SBF show the presence of two band at 605 and $654 \mathrm{~cm}^{-1}$ confirming the crystallization of an apatite-like phase. However, for the sample K_3.6 in the range characteristic of $\mathrm{PO}_{4}$ vibration another band at around $540 \mathrm{~cm}^{-1}$ is present. This band is attributed to the $\mathrm{CePO}_{4}$ crystal phase (see the spectra of pure $\mathrm{CePO}_{4}$ reported in Fig. 8) confirming the tendency of Ce-containing glasses to form insoluble phosphate on the glass surface during the bioactivity test. In fact, in a previous paper [41] it was demonstrated that the introduction of $\mathrm{Ce}$ in the $\mathrm{H}$ series decreases the bioactivity because the released cerium ions caused the precipitation of a Ce-containing phosphate phase.

\subsubsection{ESEM-EDS analyses}

All the studied glasses of the K series have reacted surface characterized by agglomerates with different morphologies (Fig. 9).

In particular, for the $\mathrm{K}$ and $\mathrm{K} \_1.2$ samples (Fig. 9 sections a, b, $\mathrm{c}$ and d), the darker areas correspond to the degraded glass which are free of the more mobile Na ions, whereas the bright ones are relative to an apatitic layer; the $\mathrm{Ca} / \mathrm{P}$ molar ratio ranges from 1.5-1.7 and it is near to the stoichiometric ratio of hydroxyl-apatite.

In the sample K_3.6 (Fig. 9 sections e and f) two different morphologies in the superimposed agglomerates are observed: i) particles of spherical shape formed by $\mathrm{Si}, \mathrm{Ca}, \mathrm{P}$ and $\mathrm{O}$ with a $\mathrm{Ca} / \mathrm{P}$ molar ratio ranges from 1.5-1.6; ii) particles of linear edges slightly enriched of $\mathrm{Ce}$ and markedly impoverished of Ca with respect to the spherical ones. The EDS analysis performed on these last agglomerates show a $\mathrm{Ce} / \mathrm{P}$ and $\mathrm{Ca} / \mathrm{P}$ molar ratios of 0.6 and $0.2-0.3$, respectively.

These morphological and compositional studies indicate that all the glasses are bioactive, the presence of $\mathrm{Ce}$ in the bright areas, could be related to the formation of a cerium phosphate or mixed calcium-cerium phosphate phases, as previously hypothesized by IR spectra, and as subsequently demonstrated by XRD analysis.

\subsubsection{XRD characterization}

Fig. 10 shows the XRD spectrum of the samples K_3.6, K_1.2 and $\mathrm{K}$ after 28 days of soaking in SBF solution, which is the most meaningful spectrum collected.

All the XRD plots show the presence of peaks characteristic of hydroxyl-apatite ( $\mathrm{hkl}=211,012$ and 002, JCPDS 09-0432), confirming the bioactivity of these glasses. In the sample K_3.6 peaks attributed to $\mathrm{CePO}_{4}$ (hkl = 120 and 20-2, JCPDS 32-0199) are also found. These results confirm the ability of the K-series glasses to form hydroxylapatite layers important for bioactivity. However, of Cerium, present in high \%, interacts with the phosphate ions of the SBF solution giving rise to an insoluble phosphate phase $\left(\mathrm{CePO}_{4}\right)$, that has been detected in this study for the first time.

\section{Discussion}

The comprehensive study carried out on Ce-containing potential bioactive glasses confirms that in both phosphate-free and phosphate containing glasses the cerium ions are present in both oxidation states $(3+$ and $4+)$. UV-vis spectra and XPS results clearly indicate that the relative concentration of $\mathrm{Ce}^{4+}$ is higher in the phosphate-free ones, conferring to the K-series of glasses higher bioactivity and higher catalase mimetic activity with respect to the H-series. This may be due to the absence of phosphate groups that are able to entrap and stabilize the $\mathrm{Ce}^{3+}$ ions.

In fact, both computational and experimental (XRD on heat-treated of the phosphate-containing glasses) results highlight the formation inside the glass structure of zones rich in $\mathrm{Ce}$ and $\mathrm{PO}_{4}$ units. These zones, characterized by low solubility, increase the chemical durability, delay the degradation glass process, and cause a decrement of bioactivity with respect to the pristine $(\mathrm{H})$ glass.

The analysis of the Ce-Ce clustering performed on the MD-derived structural models [61,62] (Fig. 11) carried out on the phosphate-free glasses show that the K_5.3 glass presents a higher amount of $\mathrm{Ce}$ clusters with 2- and 4-members, with respect to H_5.3 system. These $\mathrm{Ce}$-rich zones can be considered seed for $\mathrm{CeO}_{2}$ crystallization. Indeed, $\mathrm{XRD}$ measurements on heat-treated $\mathrm{Ce}$-containing glasses belonging to $\mathrm{K}$ series detects the presence of $\mathrm{CeO}_{2}$ crystal phases. 
(a)

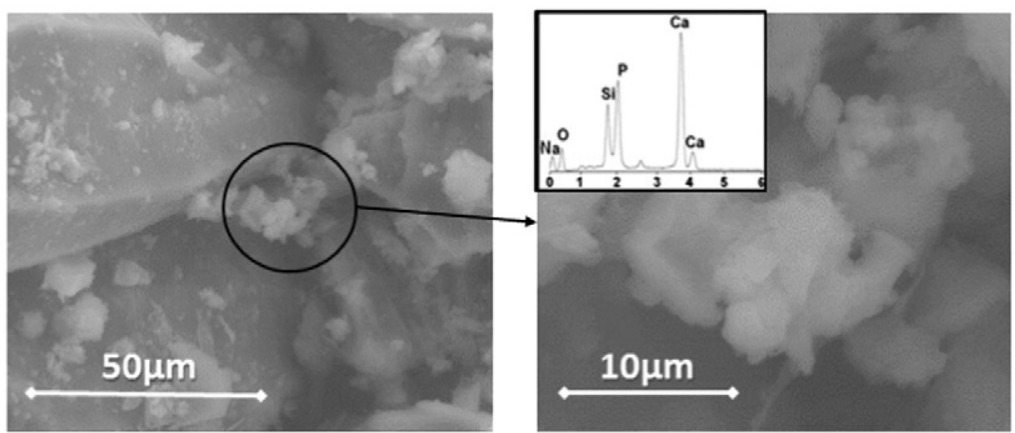

(b)

(c)

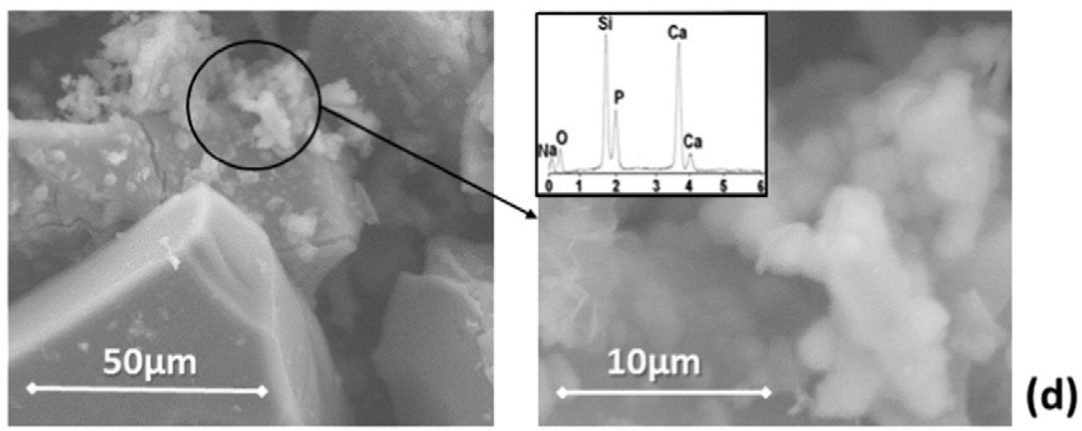

(e)

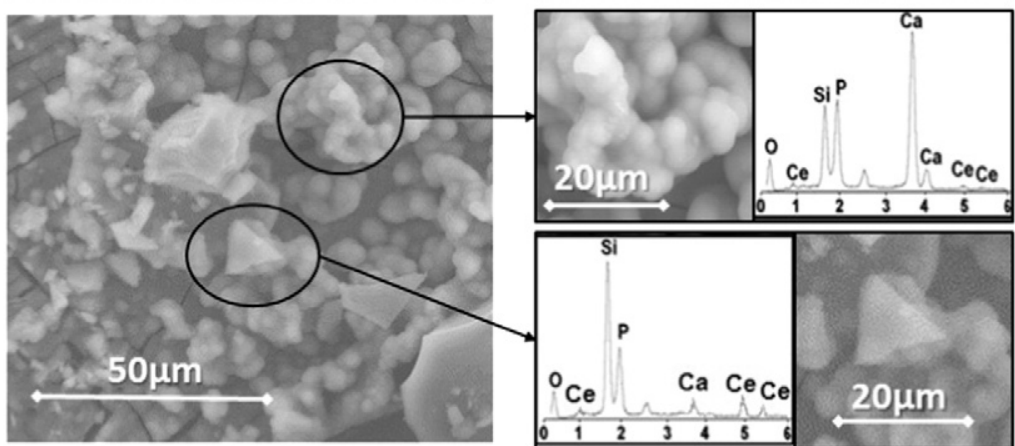

Fig. 9. Scanning electron micrographs at different magnifications ( $1000 \times$ left, $4000 \times$ right) of $K$ (a, b), K_1.2(c, d) and K_3.6 (e, f) after 28 days of soaking in SBF.

These results highlight, for the first time, a strict correlation between the behavior of Ce NPs and glasses containing $\mathrm{Ce}^{3+} / \mathrm{Ce}^{4+}$. In fact, a recent paper [63] reported on the ability of phosphate groups to inhibit the catalytic activity of Ce NPs by stabilizing the $\mathrm{Ce}^{3+}$ species preventing their oxidation to $\mathrm{Ce}^{4+}$.

Another interesting result is that the degradation of $\mathrm{H}_{2} \mathrm{O}_{2}$ is lower in SBF solutions with respect to $\mathrm{H}_{2} \mathrm{O}$ solutions; this can be explained by the XPS results obtained in the present and previous works. For the sake of clarity, some interesting data regarding the behavior of H_5.3 after soaking in $\mathrm{H}_{2} \mathrm{O}_{2}$ and $\mathrm{H}_{2} \mathrm{O}_{2}+$ SBF solutions are summarized in Table 7.

In $\mathrm{H}_{2} \mathrm{O}_{2}$ water solution a drastic decrease of the $\mathrm{Ce}^{3+} / \mathrm{Ce}^{4+}$ ratio is observed after $1 \mathrm{~h}$ of soaking, while $4 \mathrm{~h}$ of soaking are necessary to reach the same value of the ratio in $\mathrm{H}_{2} \mathrm{O}_{2}+\mathrm{SBF}$ (Table 7). Thus, the phosphatic component of the SBF solution stabilizes the $\mathrm{Ce}^{3+}$ ions present on the glass surface, preventing their conversion into the oxidized species, and delaying the depletion of $\mathrm{H}_{2} \mathrm{O}_{2}$ as shown in Fig. 5 (sections $\mathrm{a}$ and $\mathrm{b}$ ). The same phenomena are observed, albeit in a smaller extent, for the H_1.2 and H_3.6 glasses. (Fig. 7 section d, and Fig. 5 sections $\mathrm{a}$ and $\mathrm{b}$ ).

Furthermore, also the presence of the phosphate units, which constitute the structure of the $\mathrm{H}$ series of glasses, increases the stability of $\mathrm{Ce}^{3+}$ ions subtracting it from the dynamic $\mathrm{Ce}^{3+} \leftrightarrow \mathrm{Ce}^{4+}$ equilibrium fundamental for catalase mimetic activity. This explains the superior catalase mimetic activity of the $\mathrm{K}$ series with respect to the $\mathrm{H}$ series, comparing glasses with the same $\mathrm{CeO}_{2}$ content.

\section{Conclusions}

The results of this study allow the elucidation of structuralbioactivity relationships of Hench and Kokubo derived-glasses doped with Ce.

In particular, the structural role of $\mathrm{Ce}$ and the simultaneous presence of phosphate and cerium in the bulk or on the surface of the glasses have been correlated to the chemical durability (bioactivity) and the interconversion between $\mathrm{Ce}^{3+} \leftrightarrow \mathrm{Ce}^{4+}$ (catalase mimetic activity).

The influence exerted by the Ce ions on the glass connectivity and solubility of the K-derived glasses with respect to the $\mathrm{H}$ ones is due to the absence/presence of phosphate groups. In fact, phosphate groups donate $\mathrm{NBO}$ to $\mathrm{Ce}$ ions in the H-derived glasses, whereas in the $\mathrm{K}$ ones the NBOs necessary to stabilize the first coordination sphere of the Ce ions are supplied only by the de-polymerization of the silicate network. Moreover, phosphate groups stabilize the $\mathrm{Ce}^{3+}$ species, forming $\mathrm{CePO}_{4}$ insoluble phases; this prevents the interconversion process between $\mathrm{Ce}^{3+}$ and $\mathrm{Ce}^{4+}$, which is a redox reaction of fundamental importance for the exhibition of catalase mimetic activity. Therefore, the presence of phosphate groups both in the intimate glass structure and/or in the environment (SBF solution vs. pure water) causes a lower catalase mimetic activity. 


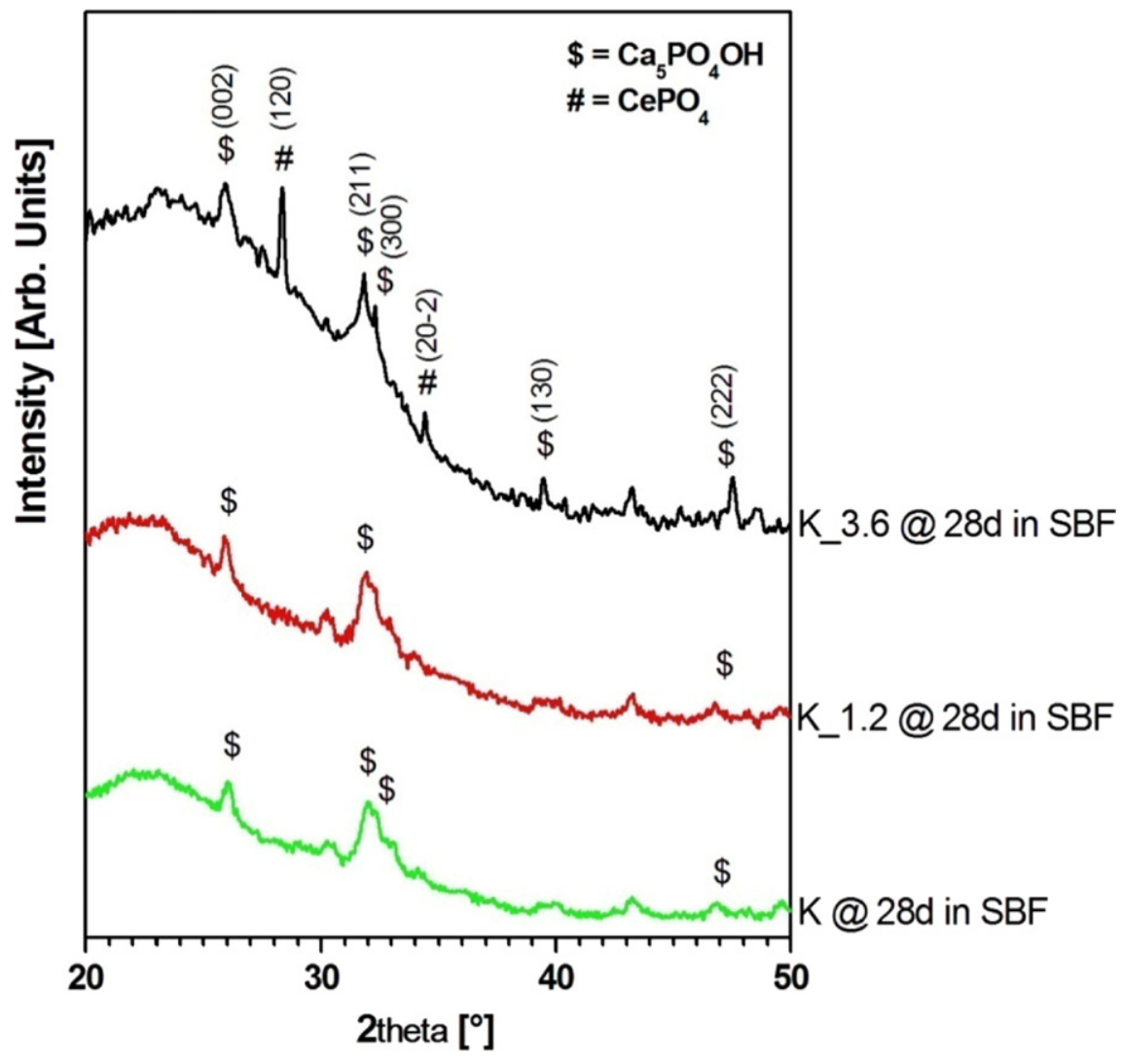

Fig. 10. XRD spectra of the K_3.6, K_1.2 and $\mathrm{K}$ samples soaked in SBF for 28 days.

\section{Acknowledgment}

This work was supported by a grant from the University of Modena and Reggio Emilia entitled 'The role of cerium oxidation state in bioactive glasses used as biomaterials of 3rd generation'. Support by the COST Action CM1104 "Reducible oxide chemistry, structure and functions" is also acknowledged.

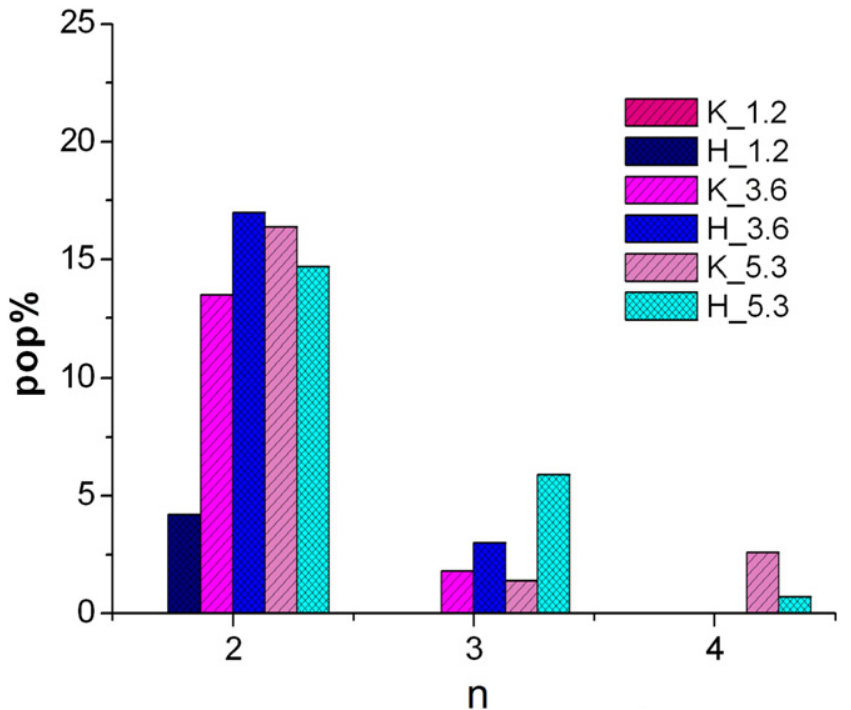

Fig. 11. Distribution of Ce clusters ( $\mathrm{n}$ is the number of the Ce ions into the cluster) in the two series of glasses (lines: K series, diamond-shape: H series).

\section{Appendix A. Supplementary data}

- Densities and size of the boxes employed in the molecular dynamic simulations are available. Table S1: Densities and size of the boxes used for the molecular dynamic simulations of the glasses of the K_series.

- UV-Vis spectra of Ce-free AQ glasses of the K and $\mathrm{H}$ series are available. Figure S1: UV - vis spectra of Ce-free glass samples with $(\mathrm{H})$ and without $(\mathrm{K})$ phosphate.

- UV-Vis spectra of glasses belonging to the H_series are available: Figure S2: UV - vis spectra of glasses belonging to the $\mathrm{H}$ _series ( $\mathrm{AQ}$ and references for $\mathrm{Ce}^{3+}$ and $\mathrm{Ce}^{4+}$ ).

Supplementary data to this article can be found online at http://dx. doi.org/10.1016/j.matdes.2016.02.056.

Table 7

Value of the $\mathrm{Ce}^{3+} / \mathrm{Ce} 4^{+}$ratio after soaking in $\mathrm{H}_{2} \mathrm{O}_{2}$ and $\mathrm{H}_{2} \mathrm{O}_{2}+\mathrm{SBF}$ for the $\mathrm{H} \_5.3$ glass.

\begin{tabular}{lcc}
\hline Time & $1 \mathrm{M} \mathrm{H}_{2} \mathrm{O}_{2}$ & $\frac{1 \mathrm{M} \mathrm{H}_{2} \mathrm{O}_{2}+\mathrm{SBF}}{\mathrm{Ce}^{3+} / \mathrm{Ce}^{4+}}$ \\
\hline 0 & $3.2^{*}$ & $\mathrm{Ce}^{3+} / \mathrm{Ce}^{4+}$ \\
$1 \mathrm{~h}$ & $1.2^{*}$ & 3.2 \\
$2 \mathrm{~h}$ & $1.4^{*}$ & 2.8 \\
$4 \mathrm{~h}$ & $1.7^{*}$ & 3.0 \\
$24 \mathrm{~h}$ & $2.1^{*}$ & 1.2 \\
$96 \mathrm{~h}$ & $1.8^{*}$ & 4.0 \\
\hline
\end{tabular}

* Data from Ref. [11]. 


\section{References}

[1] L.L. Hench, Bioceramics: from concept to clinic, J. Am. Ceram. Soc. 74 (1991) $1487-1510$

[2] L.L. Hench, R.J. Splinter, W.C. Allen, T.K. Greenlee, Bonding mechanisms at the interface of ceramic prosthetic materials, J. Biomed. Mater. Res. 5 (1971) 117-141, http://dx.doi.org/10.1002/jbm.820050611.

[3] L.L. Hench, An introduction to bioceramics, World Sci. (1993).

[4] M. Vallet-Regí, Ceramics for medical applications, J. Chem. Soc. Dalton Trans. (2001) 97-108, http://dx.doi.org/10.1039/b007852m.

[5] A.J. Salinas, A.I. Martin, M. Vallet-Regí, Bioactivity of three $\mathrm{CaO}-\mathrm{P}_{2} \mathrm{O}_{5}-\mathrm{SiO}_{2}$ sol-gel glasses, J. Biomed. Mater. Res. 61 (2002) 524-532.

[6] B. Mysen, P. Richet, Silicate glasses and melts: properties and structure, Elsevier, 2005.

[7] C. Bonhomme, C. Gervais, N. Folliet, F. Pourpoint, C. Coelho Diogo, J. Lao, et al., 87Sr solid-state NMR as a structurally sensitive tool for the investigation of materials: antiosteoporotic pharmaceuticals and bioactive glasses, J. Am. Chem. Soc. 134 (2012) 12611-12628, http://dx.doi.org/10.1021/ja303505g.

[8] E. Davies, M.J. Duer, S.E. Ashbrook, J.M. Griffin, Applications of NMR crystallography to problems in biomineralization: refinement of the crystal structure and 31P solidstate NMR spectral assignment of octacalcium phosphate, J. Am. Chem. Soc. 134 (2012) 12508-12515, http://dx.doi.org/10.1021/ja3017544.

[9] J.L. Rygel, Y. Chen, C.G. Pantano, T. Shibata, J. Du, L. Kokou, et al., Local structure of cerium in aluminophosphate and silicophosphate glasses, J. Am. Ceram. Soc. 94 (2011) 2442-2451, http://dx.doi.org/10.1111/j.1551-2916.2011.04596.x.

[10] A. Rahimnejad Yazdi, M. Towler, The effect of the addition of gallium on the structure of zinc borate glass with controlled gallium ion release, Mater. Des. 92 (2016) 1018-1027, http://dx.doi.org/10.1016/j.matdes.2015.12.082.

[11] V. Nicolini, E. Gambuzzi, G. Malavasi, L. Menabue, M.C. Menziani, G. Lusvardi, et al., Evidence of catalase mimetic activity in $\mathrm{Ce}^{3+} / \mathrm{Ce}^{4+}$ doped bioactive glasses, J. Phys. Chem. B. 119 (2015) 4009-4019, http://dx.doi.org/10.1021/jp511737b.

[12] A.L. Brioukhanov, A.I. Netrusov, Catalase and superoxide dismutase: distribution, properties, and physiological role in cells of strict anaerobes, Biochem. Biokhimiia 69 (2004) 949-962.

[13] Y. Ohno, J.I. Gallin, Diffusion of extracellular hydrogen peroxide into intracellular compartments of human neutrophils. Studies utilizing the inactivation of myeloperoxidase by hydrogen peroxide and azide, J. Biol. Chem. 260 (1985) 8438-8446.

[14] C.T. Campbell, C.H.F. Peden, Oxygen vacancies and catalysis on ceria surfaces, Science 309 (2005) 713-714, http://dx.doi.org/10.1126/science.1113955.

[15] E.G. Heckert, A.S. Karakoti, S. Seal, W.T. Self, The role of cerium redox state in the SOD mimetic activity of nanoceria, Biomaterials 29 (2008) 2705-2709, http://dx. doi.org/10.1016/j.biomaterials.2008.03.014.

[16] A.S. Karakoti, S. Singh, A. Kumar, M. Malinska, S.V.N.T. Kuchibhatla, K. Wozniak, et al., PEGylated nanoceria as radical scavenger with tunable redox chemistry, J. Am. Chem. Soc. 131 (2009) 14144-14145, http://dx.doi.org/10.1021/ja9051087.

[17] S. Deshpande, S. Patil, S.V. Kuchibhatla, S. Seal, Size dependency variation in lattice parameter and valency states in nanocrystalline cerium oxide, Appl. Phys. Lett. 87 (2005) 133113, http://dx.doi.org/10.1063/1.2061873.

[18] C. Korsvik, S. Patil, S. Seal, W.T. Self, Superoxide dismutase mimetic properties exhibited by vacancy engineered ceria nanoparticles, Chem. Commun. Camb. Engl. (2007) 1056-1058, http://dx.doi.org/10.1039/b615134e.

[19] T. Pirmohamed, J.M. Dowding, S. Singh, B. Wasserman, E. Heckert, A.S. Karakoti, et al., Nanoceria exhibit redox state-dependent catalase mimetic activity, Chem. Commun. 46 (2010) 2736, http://dx.doi.org/10.1039/b922024k.

[20] M. Das, S. Patil, N. Bhargava, J.-F. Kang, L.M. Riedel, S. Seal, et al., Auto-catalytic ceria nanoparticles offer neuroprotection to adult rat spinal cord neurons, Biomaterials 28 (2007) 1918-1925, http://dx.doi.org/10.1016/j.biomaterials.2006.11.036.

[21] A.S. Karakoti, O. Tsigkou, S. Yue, P.D. Lee, M.M. Stevens, J.R. Jones, et al., Rare earth oxides as nanoadditives in 3-D nanocomposite scaffolds for bone regeneration, J. Mater. Chem. 20 (2010) 8912, http://dx.doi.org/10.1039/c0jm01072c.

[22] H. Zhang, X. He, Z. Zhang, P. Zhang, Y. Li, Y. Ma, et al., Nano- $\mathrm{CeO}_{2}$ exhibits adverse effects at environmental relevant concentrations, Environ. Sci. Technol. 45 (2011) 3725-3730, http://dx.doi.org/10.1021/es103309n.

[23] S. Singh, T. Dosani, A.S. Karakoti, A. Kumar, S. Seal, W.T. Self, A phosphate-dependent shift in redox state of cerium oxide nanoparticles and its effects on catalytic properties, Biomaterials 32 (2011) 6745-6753, http://dx.doi.org/10.1016/j.biomaterials. 2011.05.073.

[24] H.-M. Kim, F. Miyaji, T. Kokubo, C. Ohtsuki, T. Nakamura, Bioactivity of $\mathrm{Na}_{2} \mathrm{O}-$ $\mathrm{CaO}-\mathrm{SiO}_{2}$ glasses, J. Am. Ceram. Soc. 78 (1995) 2405-2411, http://dx.doi.org/ 10.1111/j.1151-2916.1995.tb08677.x.

[25] A.L.B. Maçon, T.B. Kim, E.M. Valliant, K. Goetschius, R.K. Brow, D.E. Day, et al., A unified in vitro evaluation for apatite-forming ability of bioactive glasses and their variants, J. Mater. Sci. Mater. Med. 26 (2015)http://dx.doi.org/10.1007/s10856-015-5403-9.

[26] M. Romeo, K. Bak, J. El Fallah, F. Le Normand, L. Hilaire, XPS Study of the reduction of cerium dioxide, Surf. Interface Anal. 20 (1993) 508-512, http://dx.doi.org/10.1002/ sia.740200604.

[27] T. Skála, F. Šutara, M. Škoda, K.C. Prince, V. Matolín, Palladium interaction with $\mathrm{CeO}_{2}$, $\mathrm{Sn}-\mathrm{Ce}-\mathrm{O}$ and Ga-Ce-O layers, J. Phys. Condens. Matter 21 (2009) 055005, http:// dx.doi.org/10.1088/0953-8984/21/5/055005.

[28] E. Gambuzzi, A. Pedone, On the structure of Ce-containing silicophosphate glasses: a core-shell molecular dynamics investigation, Phys. Chem. Chem. Phys. 16 (2014) 21645-21656, http://dx.doi.org/10.1039/C4CP02577F.

[29] W.Smith, T.R. Forester, DL_POLY_2.0: a general-purpose parallel molecular dynamics simulation package, J. Mol. Graph. 14 (1996) 136-141, http://dx.doi.org/10.1016/ S0263-7855(96)00043-4.
[30] A. Pedone, Properties calculations of silica-based glasses by atomistic simulations techniques: a review, J. Phys. Chem. C 113 (2009) 20773-20784, http://dx.doi.org/ 10.1021/jp9071263.

[31] A.I. Priven, Calculation of the viscosity of glass-forming melts: V. binary borate systems, Glass Phys. Chem. 26 (2000) 541-558, http://dx.doi.org/10.1023/A: 1007196013464.

[32] V.K. Leko, O.V. Mazurin, Analysis of regularities in composition dependence of the viscosity for glass-forming oxide melts: II. viscosity of ternary alkali aluminosilicate melts, Glass Phys. Chem. 29 (2003) 16-27, http://dx.doi.org/10.1023/A: 1022301608310.

[33] A. Tilocca, Short- and medium-range structure of multicomponent bioactive glasses and melts: an assessment of the performances of shell-model and rigid-ion potentials, J. Chem. Phys. 129 (2008) 084504, http://dx.doi.org/10.1063/1.2972146.

[34] A. Pedone, G. Malavasi, M.C. Menziani, Computational insight into the effect of $\mathrm{CaO} /$ $\mathrm{MgO}$ substitution on the structural properties of phospho-silicate bioactive glasses, J. Phys. Chem. C 113 (2009) 15723-15730, http://dx.doi.org/10.1021/jp904131t.

[35] G. Malavasi, A. Pedone, M.C. Menziani, Study of the structural role of gallium and aluminum in $45 \mathrm{~S} 5$ bioactive glasses by molecular dynamics simulations, J. Phys. Chem. B. 117 (2013) 4142-4150.

[36] E. Gambuzzi, A. Pedone, M.C. Menziani, F. Angeli, D. Caurant, T. Charpentier, Probing silicon and aluminium chemical environments in silicate and aluminosilicate glasses by solid state NMR spectroscopy and accurate first-principles calculations, Geochim. Cosmochim. Acta 125 (2014) 170-185, http://dx.doi.org/10.1016/j.gca.2013.10.025.

[37] R.I. Ainsworth, D.D. Tommaso, J.K. Christie, N.H. de Leeuw, Polarizable force field development and molecular dynamics study of phosphate-based glasses, J. Chem. Phys. 137 (2012) 234502, http://dx.doi.org/10.1063/1.4770295.

[38] A. Pedone, E. Gambuzzi, M.C. Menziani, Unambiguous description of the oxygen environment in multicomponent aluminosilicate glasses from 170 solid state NMR computational spectroscopy, J. Phys. Chem. C 116 (2012) 14599-14609.

[39] A. Pedone, E. Gambuzzi, G. Malavasi, M.C. Menziani, First-principles simulations of the $27 \mathrm{Al}$ and 170 solid-state NMR spectra of the $\mathrm{CaAl}_{2} \mathrm{Si}_{3} \mathrm{O}_{10}$ glass, Theor. Chem. Accounts 131 (2012) 1-11, http://dx.doi.org/10.1007/s00214-012-1147-5.

[40] A. Tilocca, N.H. de Leeuw, A.N. Cormack, Shell-model molecular dynamics calculations of modified silicate glasses, Phys. Rev. B 73 (2006) 104209, http://dx.doi.org/ 10.1103/PhysRevB.73.104209.

[41] C. Leonelli, G. Lusvardi, G. Malavasi, L. Menabue, M. Tonelli, Synthesis and characterization of cerium-doped glasses and in vitro evaluation of bioactivity, J. Non-Cryst. Solids 316 (2003) 198-216, http://dx.doi.org/10.1016/S0022-3093(02)01628-9.

[42] J.K. Goodyear, V.L. Lindberg, Low absorption float glass for back surface solar reflectors, Sol. Energy Mater. 3 (1980) 57-67, http://dx.doi.org/10.1016/01651633(80)90049-0.

[43] H. Ebendorff-Heidepriem, D. Ehrt, Formation and UV absorption of cerium, europium and terbium ions in different valencies in glasses, Opt. Mater. 15 (2000) 7-25, http://dx.doi.org/10.1016/S0925-3467(00)00018-5.

[44] G. Ranga Rao, H.R. Sahu, XRD and UV-vis diffuse reflectance analysis of $\mathrm{CeO}_{2}-\mathrm{ZrO}_{2}$ solid solutions synthesized by combustion method, J. Chem. Sci. 113 (2001) 651-658, http://dx.doi.org/10.1007/BF02708797.

[45] C. Binet, A. Badri, J.-C. Lavalley, A spectroscopic characterization of the reduction of ceria from electronic transitions of intrinsic point defects, J. Phys. Chem. 98 (1994) 6392-6398, http://dx.doi.org/10.1021/j100076a025.

[46] M. Tomozawa, R.H. Doremus, Glass I treatise on materials science and technology Vol. 12, Elsevier Science, Burlington, 2013 (http://public.eblib.com/choice/ PublicFullRecord.aspx?p=1839140, (accessed January 19, 206)).

[47] G. Lusvardi, G. Malavasi, L. Menabue, M.C. Menziani, Synthesis, characterization, and molecular dynamics simulation $\mathrm{Of}_{2} \mathrm{O}-\mathrm{CaO}-\mathrm{SiO}_{2}-\mathrm{ZnO}$ glasses, J. Phys. Chem. B. 106 (2002) 9753-9760, http://dx.doi.org/10.1021/jp020321s.

[48] J. Du, L. Kokou, J.L. Rygel, Y. Chen, C.G. Pantano, R. Woodman, et al., Structure of cerium phosphate glasses: molecular dynamics simulation: structure of cerium phosphate glasses, J. Am. Ceram. Soc. 94 (2011) 2393-2401, http://dx.doi.org/10. 1111/j.1551-2916.2011.04514.x.

[49] L. Kokou, J. Du, Short- and medium-range structures of cerium aluminophosphate glasses: a molecular dynamics study, J. Non-Cryst. Solids 403 (2014) 67-79, http://dx.doi.org/10.1016/j.jnoncrysol.2014.07.014.

[50] Richard K. Brow, A.K. Wittenauer, Rare earth coordination environments in ultraphosphate glasses, Proc. 4th Int. Symp. Inorg. Phosphate Mater, Jena, Germany 2002, pp. 95-100.

[51] G. Mountjoy, Molecular dynamics, diffraction and EXAFS of rare earth phosphate glasses compared with predictions based on bond valence, J. Non-Cryst. Solids 353 (2007) 2029-2034, http://dx.doi.org/10.1016/j.jnoncrysol.2007.02.027.

[52] J.M. Cole, E.R.H. van Eck, G. Mountjoy, R. Anderson, T. Brennan, G. Bushnell-Wye, et al., An X-ray diffraction and ${ }^{31} \mathrm{P}$ MAS NMR study of rare-earth phosphate glasses, $\left(\mathrm{R}_{2} \mathrm{O}_{3}\right)_{x}\left(\mathrm{P}_{2} \mathrm{O}_{5}\right)_{1-x}, x=0.175-0.263, \mathrm{R}=\mathrm{La}, \mathrm{Ce}, \mathrm{Pr}, \mathrm{Nd}, \mathrm{Sm}, \mathrm{Eu}, \mathrm{Gd}, \mathrm{Tb}, \mathrm{Dy}, \mathrm{Ho}, \mathrm{Er}, \mathrm{J}$ Phys. Condens. Matter. 13 (2001) 4105-4122, http://dx.doi.org/10.1088/09538984/13/18/318.

[53] A. Tilocca, A.N. Cormack, N.H. de Leeuw, The structure of bioactive silicate glasses: new insight from molecular dynamics simulations, Chem. Mater. 19 (2007) 95-103, http://dx.doi.org/10.1021/cm061631g.

[54] J.K. Christie, A. Pedone, M.C. Menziani, A. Tilocca, Fluorine environment in bioactive glasses: ab initio molecular dynamics simulations, J. Phys. Chem. B. 115 (2011) 2038-2045, http://dx.doi.org/10.1021/jp110788h.

[55] E. Gambuzzi, T. Charpentier, M.C. Menziani, A. Pedone, Computational interpretation of 23Na MQMAS NMR spectra: a comprehensive investigation of the Na environment in silicate glasses, Chem. Phys. Lett. 612 (2014) 56-61, http://dx.doi.org/10. 1016/j.cplett.2014.08.004.

[56] E. Gambuzzi, A. Pedone, M.C. Menziani, F. Angeli, P. Florian, T. Charpentier, Calcium environment in silicate and aluminosilicate glasses probed by 43Ca MQMAS NMR 
experiments and MD-GIPAW calculations, Solid State Nucl. Magn. Reson. (2015), http://dx.doi.org/10.1016/j.ssnmr.2015.04.003.

[57] J.R. Jones, Review of bioactive glass: from Hench to hybrids, Acta Biomater. 9 (2013) 4457-4486, http://dx.doi.org/10.1016/j.actbio.2012.08.023.

[58] G. Pulido-Reyes, I. Rodea-Palomares, S. Das, T.S. Sakthivel, F. Leganes, R. Rosal, et al., Untangling the biological effects of cerium oxide nanoparticles: the role of surface valence states, Sci. Report. 5 (2015) 15613, http://dx.doi.org/10.1038/srep15613.

[59] S.V.N.T. Kuchibhatla, A.S. Karakoti, D.R. Baer, S. Samudrala, M.H. Engelhard, J.E. Amonette, et al., Influence of aging and environment on nanoparticle chemistry: Implication to confinement effects in nanoceria, J. Phys. Chem. C 116 (2012) 14108-14114, http://dx.doi.org/10.1021/jp300725s.

[60] M. Vallet-Regí, I. Izquierdo-Barba, A.J. Salinas, Influence of $\mathrm{P}_{2} \mathrm{O}_{5}$ on crystallinity of apatite formed in vitro on surface of bioactive glasses, J. Biomed. Mater. Res. 46
(1999) 560-565, http://dx.doi.org/10.1002/(SICI)1097-4636(19990915)46:4< 560::AID-JBM14>3.0.CO;2-M.

[61] V.R. Mastelaro, E.D. Zanotto, N. Lequeux, R. Cortès, Relationship between shortrange order and ease of nucleation in $\mathrm{Na}_{2} \mathrm{Ca}_{2} \mathrm{Si}_{3} \mathrm{O}_{9}, \mathrm{CaSiO}_{3}$ and $\mathrm{PbSiO}_{3}$ glasses, J. Non-Cryst. Solids 262 (2000) 191-199, http://dx.doi.org/10.1016/S00223093(99)00685-7.

[62] J. Schneider, V.R. Mastelaro, H. Panepucci, E.D. Zanotto, 29Si MAS-NMR studies of Qn structural units in metasilicate glasses and their nucleating ability, J. NonCryst. Solids 273 (2000) 8-18, http://dx.doi.org/10.1016/S0022-3093(00)00139-3.

[63] R.N. McCormack, P. Mendez, S. Barkam, C.J. Neal, S. Das, S. Seal, Inhibition of Nanoceria's catalytic activity due to $\mathrm{Ce} 3+$ site-specific interaction with phosphate ions, J. Phys. Chem. C 118 (2014) 18992-19006, http://dx.doi.org/10.1021/ jp500791j. 